\title{
Systemic Analysis of the Contributions of Co-Located Industrial Symbiosis to Achieve Sustainable Development in an Industrial Park in Northern Spain
}

\author{
Carmen Ruiz-Puente and Daniel Jato-Espino *D \\ INGEPRO Research Group, Department of Transport and Projects and Processes Technology, University of \\ Cantabria, 39005 Santander, Spain; mdelcarmen.ruiz@unican.es \\ * Correspondence: jatod@unican.es
}

Received: 16 June 2020; Accepted: 16 July 2020; Published: 19 July 2020

check for updates

\begin{abstract}
Resource efficiency is a strategy with great potential to make progress towards the UN Sustainable Development Goals (SDGs), since it can contribute to meeting a variety of economic, environmental and social targets. In this context, this investigation developed a systemic analysis of co-located Industrial Symbiosis (IS) synergies in an industrial park formed of four companies. To this end, public data showing that the main activity in this park concerned materials, water and steam flows were supported with short visits to the companies for verification purposes. Then, the effects of nine exchange and twelve share synergies were analysed at different scales according to their impacts on sustainable development. The changes caused by these synergies in the flows in the industrial park enabled saving more than $10 \mathrm{k}$ tonnes of raw materials and waste disposal and almost $10 \mathrm{Mm}^{3}$ of raw water per year, as well as six auxiliary service systems. In the end, these figures might be translated into more than $200 \mathrm{kt} \mathrm{CO}_{2}$ eq. and EUR 6M saved per year, which in turn corresponds to $0.05 \%$ of the Gross Domestic Product (GDP) of the region in which the park is located. In terms of sustainable development, these modifications were translated into contributions to nine SDGs and 14 of their specific targets, proving the domino effect associated with the application of IS policies by governments and public entities.
\end{abstract}

Keywords: circular economy; systems thinking; industrial symbiosis; resource sharing; steam; sustainable development; synergy; industrial sustainability

\section{Introduction}

Resource efficiency has been proposed by the UNEP International Resource Panel (IRP) as a means to decouple economic growth from environmental deterioration while protecting human well-being, which is crucial for achieving the Sustainable Development Goals (SDGs) [1]. The worldwide consumption of primary materials was 90 billion tons by 2017, a figure which is expected to increase up to 186 billion tons by 2050 [2]. This trend has resulted in diverse negative impacts on soils, aquifers and biodiversity, whilst increasing food and water demands.

Industrial Ecology (IE) has been found to have huge potential to attenuate the effects of these harmful prospects [3]. IE is an interdisciplinary area whose goal is to reproduce the characteristics of natural ecosystems in the industry, closing material loops and searching for sustainable development [4]. Hence, IE requires industrial areas not to be isolated with respect to their surroundings, but considered alongside them to optimize the handling of resources from extraction to disposal [5]. Apart from this global and systemic vision of the industry as a natural ecosystem, IE must be based on the creation of dynamic networks of entities or companies within their area and the promotion of sustainable development [6]. In this vein, the retrofitting of industries by increasing resource efficiency has been identified as a means to contribute to the SDGs [7]. 
Industrial Symbiosis (IS) is a branch of IE aimed at creating cooperation networks whereby two or more industrial entities carry out mutually beneficial relationships, with emphasis on cases in which one entity makes productive use of streams that are considered as wastes by another [8]. The other main means of symbiotic association concerns the shared use of facilities, equipment and/or utilities for saving resources purposes [9]. As a result, there is a reduction in the amount of waste and emissions, as well as economic advantages for the industrial entities involved [10]. Geographical proximity is an essential factor in facilitating IS [11], since it increases the feasibility of opportunities through which to exchange products and/or share components [12]. Despite the additional complexity entailed by IS practices in relation to other alternatives (e.g., direct disposal), IS has been found to be capable of producing economic and environmental benefits at regional scales [13].

As a result, the principles of IS crystallize in Eco-Industrial Parks (EIP), which consist of communities of companies located in a common area that seek to improve economic, environmental and social performance through collaboration in managing resources [14]. EIPs differ from other forms of cooperation such as industrial clusters, whose main focus is to gain economic benefits and, therefore, disregards other aspects of sustainability [15]. They also differ from industrial districts, which are more specific and mostly refer to co-located small and medium companies devoted to light manufacturing sectors of the economy [16]. Although all these terms have limited geographic boundaries, they are closely linked to regional innovation systems, which in turn relate to the existence of learning experiences based on localized nodes of industrial activity. These nodes can lead to developing policies whereby a region is considered the most suitable scale to foster innovation-based economies [17].

Under these premises, the research community has produced a variety of scientific studies to explore the nexus between IE (including IS and EIPs), systems engineering and sustainability. More than two decades ago, Côte and Cohen (1998) [18] highlighted the need for widening the perspective on EIPs, which tended to be limited to waste exchange, and used a systems-approach to involve environmental, economic and social aspects within and outside of the park. In this vein, Haskins (2006) [19] studied existing eco-industrial developments and pointed out the adoption of regional approaches to achieve stable and sustainable ecosystems. This path was found to be hindered by geographic dispersion, as well as by additional efforts in terms of trust, coordination and data collection. As a contribution to deal with these barriers, the same author proposed [20] and applied [21] a systems framework to form and sustain industrial parks, including aspects such as stakeholder coordination, interdisciplinarity, unification and monitoring. The use of indicators to track sustainable development progress was identified as one of the main lines of additional work to develop. Similarly, Sopha et al. (2010) [22] built a systems framework for assessing IS, including its application through a case study. Although the approach served for stakeholder identification and reveals the need and means to solve the problem under consideration, facilitating communication was argued to be a field to explore in the future. The dynamic nature of EIPs was also addressed by Romero and Ruiz (2013) [23], who developed a framework expected to form the basis on which to build mathematical models for analyzing EIPs. Their objectives, surroundings and the relationships and decisions of stakeholders were underlined as key features to properly modelling these systems.

The link between territorial policies and sustainability was explored by Deshpande and Aspen (2018) [24], who provided a systems engineering framework to ensure sustainable resource management. The approach taken was found to facilitate the nexus between the SDGs and policymakers, such that the latter gained understanding of a complex process and improved their decision-making. In relation to the SDGs focused on zero poverty and hunger, Ginige (2018) [25] combined systems engineering with smart computing to support the coordination of agricultural production in Sri Lanka. The proposed framework was presented to provide a long-term solution to the complex multi-disciplinary nature of this problem. On a smaller scale, Moldavska and Welo (2019) [26] defined a corporate sustainability assessment method based on systems thinking to measure the links of manufacturing companies with the SDGs. The proposed approach proved to address the shortcomings of previous methods by using a set of sustainability criteria. This was in line with the perspective of van den Hoven (2019) [20], who emphasized the need for using a systemic and 
comprehensive engineering approach to couple technical issues with social and ethical aspects. Brooks (2020) [27] explored the link between systems engineering and the SDGs by adopting a design science research method to examine the elicitation of sustainability requirements in aerospace and healthcare facilities. The preliminary results achieved suggested that the application of the proposed method may lead to the enhanced coverage of the SDGs in most organizations.

The trend of these studies showed that previous research focused on developing theoretical frameworks to couple systems engineering with the monitoring of the SDGs. However, their use for cultivating symbiotic relationships in EIPs is still limited, especially under the consideration of how these potential processes of IS might contribute to achieving the SDGs. Therefore, this revealed a gap in what concerns the assessment of IS in industrial systems, whereby synergies are presented and analysed to assist public and private sector organizations in developing and implementing EIPs. This needs to be supported with an examination of the potential benefits that IS may have at meso (city and region) and macro (country) scales, including their evaluation using the SDGs as a benchmark. Consequently, this research concerned the identification of synergies in an industrial park, their analysis at different scales and the relationships of such synergies with the targets forming the SDGs, thereby providing an overview of the contributions of IS to sustainable development.

The rest of the article is structured as follows: Section 2 includes the methodology proposed to collect and process the data characterizing the main companies in the industrial park under study, as well as the framework used to value the contributions of synergies to be identified in terms of sustainable development. Section 3 starts by describing and illustrating the situation of the three main flows (materials, water and steam) in the industrial park. Then, potential direct and indirect synergies are overviewed according to their feasibility, such that a set of opportunities is selected and assessed based on their impacts of the three flows under consideration, The section ends with the estimation and discussion of the benefits to which these synergies may lead, emphasizing their associated economic and environmental savings. Finally, Section 4 contains the main findings of the study, highlighting both their implications for its research field and future lines of action to address its limitations.

\section{Materials and Methods}

The approach taken to conduct this research is depicted in Figure 1. It stemmed from a collaboration agreement between the city council to which the industrial park under study belongs and the university of the region. Therefore, the project involved the three main stakeholders required for promoting IS, namely public institutions, research centres and private companies, whose interests focused on welfare, knowledge and benefits, respectively. In this vein, the results to be obtained in this study were expected to work as the basis for developing future IS projects in the city. To this end, first was the acquisition of information from the public Integrated Environmental Authorisations (IEA) of the main companies (C1-C4) in the industrial park. Then, guided visits to their facilities and work sessions were arranged to corroborate these data and understand the processes leading to them. Finally, an analysis of potential IS opportunities in this industrial park was undertaken by taking into account both the contributions of the identified synergies to sustainable development and their scaling to regional and national levels.

\subsection{Study Area and Industrial Park Description}

The industrial park under study is located in the north of Spain and formed of more than 100 companies, most of which belong to a first subsystem of small and medium-sized enterprises (SMEs). Still, the four large companies forming the second subsystem are responsible for most of the material and energy resources in the area. Furthermore, since the park is an open industrial ecosystem, they can perform as a node to enable potential expansions involving other companies and/or industrial parks within the city or region. Consequently, this study focused on these dominant companies, since they might act as a catalyst in terms of IS due to their intense activity and turnover. Data for the characterization of these companies were acquired from their IEAs, which contain their global resource 
flows and can be publicly accessed on the official bulletin of their region. Nevertheless, in no case will details about the location and names of these companies be disclosed, since confidentiality has been maintained to prevent any leakage of sensitive information. Suffice it to state that the distance separating the companies is as follows: $2.6 \mathrm{~km}(\mathrm{C} 1-\mathrm{C} 2), 0.7 \mathrm{~km}(\mathrm{C} 1-\mathrm{C} 3), 2.7 \mathrm{~km}(\mathrm{C} 1-\mathrm{C} 4), 2.15 \mathrm{~km}$ (C2-C3), $4.0 \mathrm{~km}(\mathrm{C} 2-\mathrm{C} 4)$ and $2.3 \mathrm{~km}(\mathrm{C} 3-\mathrm{C} 4)$.

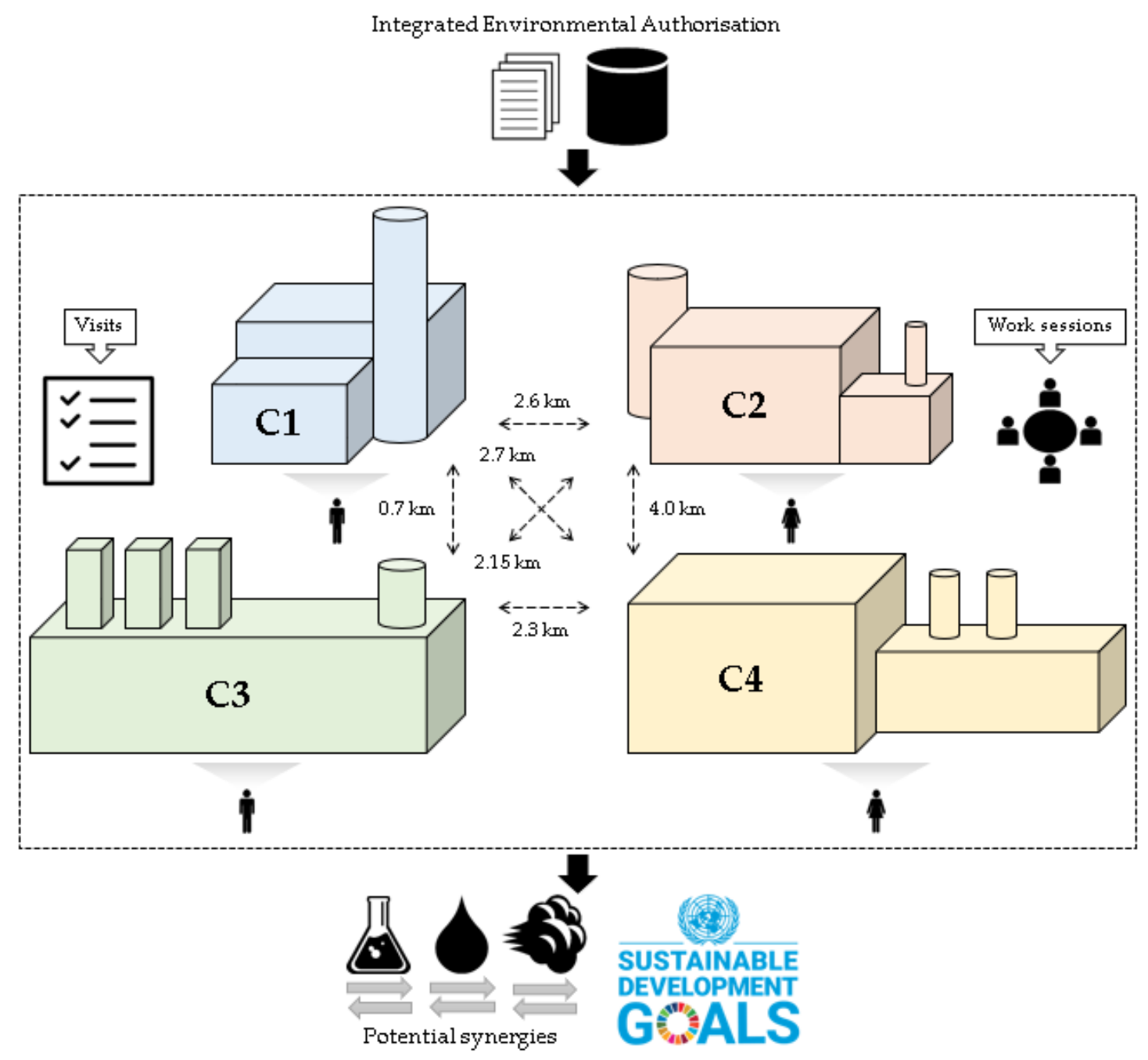

Figure 1. Graphical abstract of the steps taken to carry out a systemic analysis of Industrial Symbiosis (IS) synergies in an industrial park in the context of the Sustainable Development Goals (SDGs).

$\mathrm{C} 1$ was a company devoted to the conversion of plastic materials into flexible packaging and amounted to 490 employees on the date the study was conducted. With 466 workers, the area targeted by $\mathrm{C} 2$ was the manufacture of tires for private cars, trucks, tractor and industrial vehicles, pre-rolled treads and compound strips. C3 was the largest company, with 517 employees operating in facilities for the production, distribution and/or treatment of cellulose, inorganic chemical products (gas), electric energy, pressurized steam, viscose fibre, sodium sulphate organic chemical products (plastic materials and salts). Finally, C4 staff (463 people) were dedicated to several production processes with multiple applications, such as manufacturing of sodium carbonate, electrolysis, preparation of hydrogen peroxide solutions and cogeneration with thermal coal and cooling systems.

The input and output patterns observed in the companies forming the industrial park led to limiting the study to three flows: materials, water and steam. This particular trio of flows was selected because of their predominance in the activities carried out in the industrial park and their greater potential impacts with respect to others such as electricity, compressed air, nitrogen and fuels. Materials 
included raw materials, auxiliary materials and auxiliary production services, as well as the wastes derived from their production, such as hazardous and non-hazardous substances and emissions and discharges to air and water. Water included the consumption and waste flows required for its analysis as a resource, without taking into account temperature. Finally, steam concerned water thermal flows used in the companies as a process fluid or for power generation purposes.

\subsection{Preparation of Questionnaires}

The first step to undertake an inventory gathering information about the activity of the companies in the industrial park was the delimitation of the systems included in a company. According to Casals et al. (2008) [28], a company can be divided into five systems: management, operations, finance, marketing and human resources. Since the circulation of physical resources within the companies mainly concerns the operations system, this was the focus of the study hereinafter. This system refers to the set of activities oriented to the transformation of raw materials into products or the production of services demanded by the market, as well as to the auxiliary tasks required to carry out such processes. Material, water and steam flows circulate throughout several areas forming the operations system, such as production, auxiliary systems, general systems, waste treatment, storage and staff services.

With the support of these concepts, a questionnaire was designed to inventory data describing the different flows present in the industrial park. This questionnaire was structured according to three main parts: (1) an introduction showing the proposed workflow and a glossary of terms, (2) general information that must be provided by the companies regarding their organization and location maps and (3) specific data to be collected during the visits about the input, distribution and output flows in the companies. As proofs of the contents of these questionnaires, Supplementary Materials shows the data requested to compile information about the three flows analysed in this study: materials, water and steam. The questionnaires were filled out during short stays in the four companies forming the industrial park during 2011, in order to gather information about materials, water and steam flow inputs and outputs, as well as their distribution in the companies. The questionnaire was sent in advance to the technical coordinators of the companies to guarantee the effectiveness of the stays, which were divided into two main components: visits to facilities and office works sessions. The former were supported with explanations by technicians regarding the processes in their respective companies, whilst the latter consisted of putting together the information collected about the different flows, enabling the completion of the questionnaire.

\subsection{Processing and Analysis of Data and Identification of Synergies}

Once the stays were over, the data collected were processed and analysed according to the following sequence: inventory, flow schemes and floor plans. The inventory consisted of organising and simplifying the data collected during the stays independently for each company, and then combining them to represent the whole industrial park. Flow data were arranged to include quality specifications and details about the generation, distribution and treatment facilities, specifying their nominal and maximum capacities. Finally, the analysis was completed with the floor plans of the industrial park. Although this information was not strictly necessary for the identification of synergies, their consideration enabled the determination of the preliminary technical viability of some of them by locating consumption and waste generation spots.

The processing and analysis of data was the premise required for the identification of synergies. From a conceptual point of view, this research considered two types of synergies: substitution and mutuality. The former consists of replacing the consumption of input flows in a company by waste or output flows from another company, such that there is a reduction in resource needs and environmental impacts. Unlike this type of synergies in the form of exchanges, mutuality synergies refer to the shared use of services and/or infrastructures between different companies. In line with the most recent developments in the field of IS at the European level, the terminology used in the SCALER project [29] was adopted for this investigation. This project, which aimed at increasing the uptake of IS across 
Europe through a systemic approach that considered all stakeholders, translated exchange and sharing practices into direct and indirect synergies, respectively. The criteria followed for the identification of materials, water and steam synergies in the industrial park are summarised in Table 1.

Table 1. Considerations for the identification of materials, water and steam synergies.

\begin{tabular}{|c|c|c|c|}
\hline Flow & Synergy & Description & Parameters \\
\hline \multirow{4}{*}{ Materials } & Direct & Use of wastes as raw materials & Type and amount of materials and wastes \\
\hline & Indirect & Shared supply & Type and amount of materials \\
\hline & & Shared storage & Type and amount of materials; Storage capacity \\
\hline & Indirect & Joint management of waste & $\begin{array}{l}\text { Type and amount of wastes; } \\
\text { Current management }\end{array}$ \\
\hline \multirow{3}{*}{ Water } & Direct & Use of wastewater as raw water & $\begin{array}{c}\text { Type and amount of raw water; Raw water uses; } \\
\text { Water with similar quality; Type and amount of } \\
\text { wastewater; Wastewater destination }\end{array}$ \\
\hline & Indirect & Shared collection & $\begin{array}{c}\text { Type and amount of raw water; Raw water uses; } \\
\text { Water with similar quality }\end{array}$ \\
\hline & & Pre-treatment of water & $\begin{array}{c}\text { Type and amount of water; Water uses; } \\
\text { Ownership of facilities for water pre-treatment; } \\
\text { Pre-treatment capacity }\end{array}$ \\
\hline \multirow{2}{*}{ Steam } & Direct & $\begin{array}{l}\text { Use of non-recovered steam as } \\
\text { consumption steam }\end{array}$ & $\begin{array}{l}\text { Waste steam generation; Steam consumption; } \\
\text { Physical characteristics of waste and } \\
\text { consumption steam }\end{array}$ \\
\hline & Indirect & $\begin{array}{l}\text { Shared supply } \\
\text { Supply from one company to another }\end{array}$ & $\begin{array}{l}\text { Production and consumption } \\
\text { Production and consumption; Supply capacity }\end{array}$ \\
\hline
\end{tabular}

Due to their intrinsic characteristics, materials data could not be arranged in the form of a network using an origin-destination structure based on nodes and arrows. This was because these data consisted of separate lists of different materials and wastes, without sharing intermediate processes or treatments. Instead, water and steam uses were formed of a sequence of steps going from their collection to their disposal or recirculation. Consequently, their representation differed from that of materials, whose visualization was approached through bar charts detailing the variety of substances used in the industrial park.

Regarding water and steam, their graphical depiction was addressed with the support of Sankey diagrams, which display resource flows through directed arrows whose width is proportional to the quantity represented [30]. This concept was originally published by Riall Sankey at the end of the 19th century to analyze the efficiency of steam engines [31]. The need for improving material management in the steel production sector during the 1930s popularized the application of balances with the support of Sankey diagrams [32]. Since then, they have become particularly important in industrial ecology, due to their capacity to depict all relevant flows and their interdependences [33]. This trend provides evidence of the suitability of Sankey diagrams to represent both water and steam flows.

\subsection{Industrial Symbiosis and Sustainable Development Goals (SDGs)}

The broad implications of IS, whose consideration helps to promote economic growth and the safeguarding of the environment, have great potential to unlock mechanisms aimed at fostering sustainable development [3]. These potential contributions can be measured using the Sustainable Development Goals (SDGs) as a benchmark, which are 17 objectives that were set in the United Nations Conference on Sustainable Development held in Rio de Janeiro in 2012 for the period 2015-2030 [34]. In fact, the UN International Resource Panel highlighted the ripple effect of IS on sustainability, provided by its linked benefits across different SDGs [1].

Schroeder et al. (2019) [7] identified the extent to which circular economy practices may be relevant for achieving the SDGs. Overall, they found that a circular economy can contribute with greater or lesser intensity to all SDGs, either directly or indirectly. The strongest relationships were found to correspond to the targets of SDGs 6 (Clean Water and Sanitation), 7 (Affordable and Clean Energy), 8 (Decent Work and Economic Growth), 12 (Sustainable Consumption and Production) and 
15 (Life on Land). These inferences provided an overview of the association between circular economy and the SDGs; however, further analysis is required to explore the relationships between sustainability and particular branches of circular economy, such as IS.

Hence, the synergies identified in the industrial park under study through the proposed methodology (Figure 1) were evaluated in terms of their potential contributions to achieving the 169 targets included in the SDGs. To the extent possible, this analysis was supported with coarse quantifications of the economic and environmental benefits derived from the implementation of the IS practices identified. In turn, this course of action was intended to enable making estimates about the scale effects of IS at regional and national levels.

\section{Results and Discussion}

In what concerns material flows, IS was aimed at (1) reducing the consumption of materials and the generation of wastes, (2) minimizing and centralizing the storage of input materials and wastes to increase space availability and (3) sharing supply services to save costs due to economies of scale, thereby improving the logistics in the industrial park. Overall, the consumption of virgin materials was distributed as follows: raw materials $(2,906,119 \mathrm{t} / \mathrm{yr}$., $96 \%)$, auxiliary materials $(87,061 \mathrm{t} / \mathrm{yr}$., $3 \%)$ and auxiliary production services $(34,676 \mathrm{t} / \mathrm{yr}$., $1 \%)$. Regarding the destination and type of wastes generated, 242,648 t/yr. (99.6\%) were found to be non-hazardous, which means that only $1006 \mathrm{t} / \mathrm{yr}$. $(0.4 \%)$ were hazardous.

The breakdown of materials and wastes according to their types is depicted in Figure 2. C4 was the greatest contributor to the consumption of raw materials, since it was responsible for brine and limestone, which amounted to a yearly consumption of 1,576,974 and 930,646 t. Similarly, C3 was the dominant company in the consumption of auxiliary materials and auxiliary production services, with $17,280,15,515$ and 2191.6 t/yr. of sulphuric acid, sodium hydroxide and oxygen, respectively. Regarding hazardous wastes, sludge from ink distillation processes $(253.8 \mathrm{t} / \mathrm{yr}$.) and Industrial Wastewater Treatment Plants (IWTP) (179.3 t/yr.) were the main sources of generation. The fact that calcined calcium carbonate $(205,684 \mathrm{t} / \mathrm{yr}$.) and brine $(110,000 \mathrm{t} / \mathrm{yr}$.) were the main flows in terms of non-hazardous wastes and emissions and discharges supported the feasibility of some potential synergies, since both products were consumed as materials in the industrial park (Figure 2).

Apart from generic reduction and minimization considerations as mentioned for the materials, the analysis of water flows also required taking into account the following Spanish and European standards concerning the Hydraulic Public Domain: Royal Decree-Law 995/2000 (Quality objectives for certain polluting substances), Royal Decree-Law 60/2011 (Environmental quality standards in the field of water policy), Directive 91/271/EEC (Urban wastewater treatment) and Royal Decree-Law 1620/2007 (Legal framework for the reuse of purified water).

Overall, more than $94 \%$ of water $\left(3739 \mathrm{~m}^{3} / \mathrm{h}\right.$ out of $\left.3966 \mathrm{~m}^{3} / \mathrm{h}\right)$ was captured from a river. Assuming an annual continuous work regime $(8760 \mathrm{~h})$ and according to the values represented in Figure 3, this volume amounted to $32,753,640 \mathrm{~m}^{3} / \mathrm{yr}$. Therefore, reducing the consumption of this source was a priority. From less to more quality, the types of water used by the companies are raw, filtered, clarified, decarbonated and demineralized (equivalent to osmotized). Since the most widely consumed type of water by all the companies in the industrial park was clarified $\left(2746 \mathrm{~m}^{3} / \mathrm{h}, 41 \%\right.$ of the flow processed through either coarse filtering, osmosis, clarification, demineralization, decarbonation or chlorination), this was a flow of interest for the reduction in the amount of water used in the park. A small part of the flows derived from these treatment nodes was straightforwardly connected to output nodes, since it was associated with purges. 

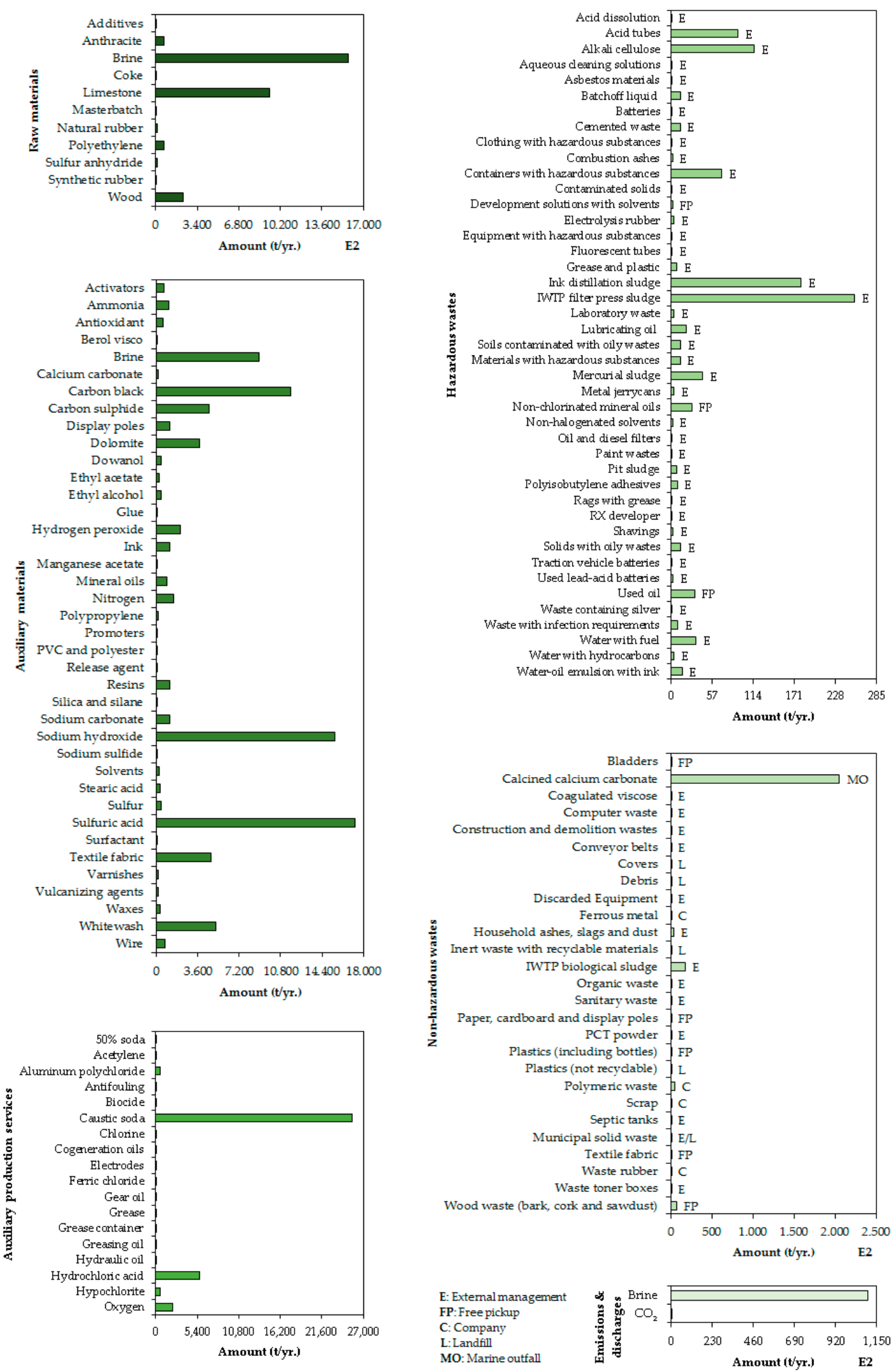

Figure 2. Breakdown of materials and wastes in the industrial park. 


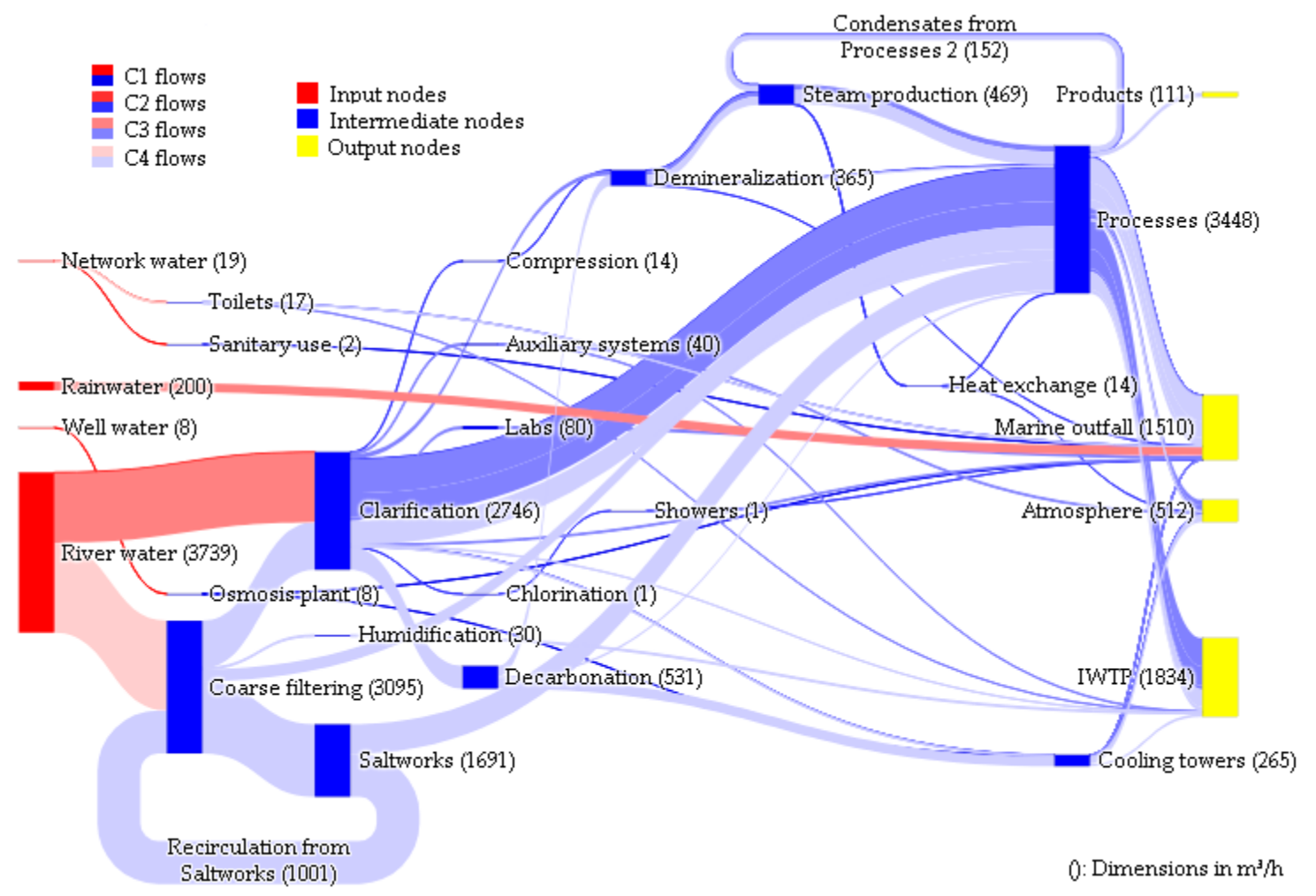

Figure 3. Sankey diagram of water flows in the industrial park.

The total flow consumed in intermediate nodes amounted to $12,811 \mathrm{~m}^{3} / \mathrm{h}$. In particular, three groups represented the main uses given to water: processes, steam production and cooling towers. These groups were taken as a criterion to determine whether any of their associated uses might admit lower quality water without compromising the performance of the companies. The highest consumption within this group corresponded to processes $\left(3448 \mathrm{~m}^{3} / \mathrm{h}, 82 \%\right)$, followed by steam production $\left(469 \mathrm{~m}^{3} / \mathrm{h}, 11 \%\right)$ and cooling towers $\left(265 \mathrm{~m}^{3} / \mathrm{h}, 7 \%\right)$.

Water destination plays an important role in this systemic analysis, since this concept is related to the minimization of discharge rates and potential reuse of water according to the implementing legislation. Most of the water used in the park was sent to an IWTP $\left(1834 \mathrm{~m}^{3} / \mathrm{h}, 46 \%\right)$, a marine outfall $\left(1510 \mathrm{~m}^{3} / \mathrm{h}, 38 \%\right)$ and the atmosphere $\left(512 \mathrm{~m}^{3} / \mathrm{h}, 13 \%\right)$. Instead, only $3 \%$ ended up being used as products $\left(111 \mathrm{~m}^{3} / \mathrm{h}\right)$.

The optimization of steam consumption in the industrial park aimed at achieving a higher efficiency in the companies and minimizing the presence of unnecessary infrastructures, while centralizing steam flows and achieving continuous operating regimes. The fulfilment of these targets was conditioned by the potential use of the steam produced in the park for generating electricity to be either sold externally or consumed in internal processes. Therefore, the approach taken to address the steam flow considered its link with electricity. The quality demands for the production of steam required demineralized water, such that $317 \mathrm{~m}^{3} / \mathrm{h}$ out of the $365 \mathrm{~m}^{3} / \mathrm{h}$ flow depicted in Figure 3 performed as an input $(317 \mathrm{t} / \mathrm{h})$ in the Sankey diagram represented in Figure 4.

The joint analysis of the four companies revealed that the steam and hot water generated in the industrial park amounted to $469 \mathrm{t} / \mathrm{h}$ (carbon boiling, gas boiling and gas cogeneration), which were produced in the range from 1.2 to $140 \mathrm{~kg} / \mathrm{cm}^{2}$. Most of this steam $(420 \mathrm{t} / \mathrm{h})$ was produced at high pressure (58-140 kg/ $\mathrm{cm}^{2}$ ) and then was turbined (Figure 4) for the generation of electric energy. The low and medium-pressure steam $\left(5.5-33 \mathrm{~kg} / \mathrm{cm}^{2}\right)$ derived from turbines, along with the remains of the production nodes $(49 \mathrm{t} / \mathrm{h})$ at $1.2-16.5 \mathrm{~kg} / \mathrm{cm}^{2}$, were used in different processes: Processes 1 involved input flows at medium pressure $\left(9-33 \mathrm{~kg} / \mathrm{cm}^{2}\right)$, such as steam recovery or drying, whilst Processes 2 (e.g., distillation) corresponded to low-pressure processes $\left(1.2-5.5 \mathrm{~kg} / \mathrm{cm}^{2}\right)$. Heat exchange 
was left apart as a single process to provide more details about $\mathrm{C} 2$, since the steam scheme of this company would be too simplified otherwise. Overall, the steam consumption in the industrial park was balanced in terms of pressure: $344 \mathrm{t} / \mathrm{h}$ were consumed at medium pressure (Processes $1+$ Heat exchange) and $303 \mathrm{t} / \mathrm{h}$ at low pressure (Processes 2 ). In the end, the steam consumed in the processes was either recirculated as condensates $(152 \mathrm{t} / \mathrm{h})$ or converted into $21 \mathrm{t} / \mathrm{h}$ of non-recovered (atmosphere) or $296 \mathrm{t} / \mathrm{h}$ of condensate steam (marine outfall and IWTP), amounting to the $317 \mathrm{t} / \mathrm{h}$ that originally entered the system.

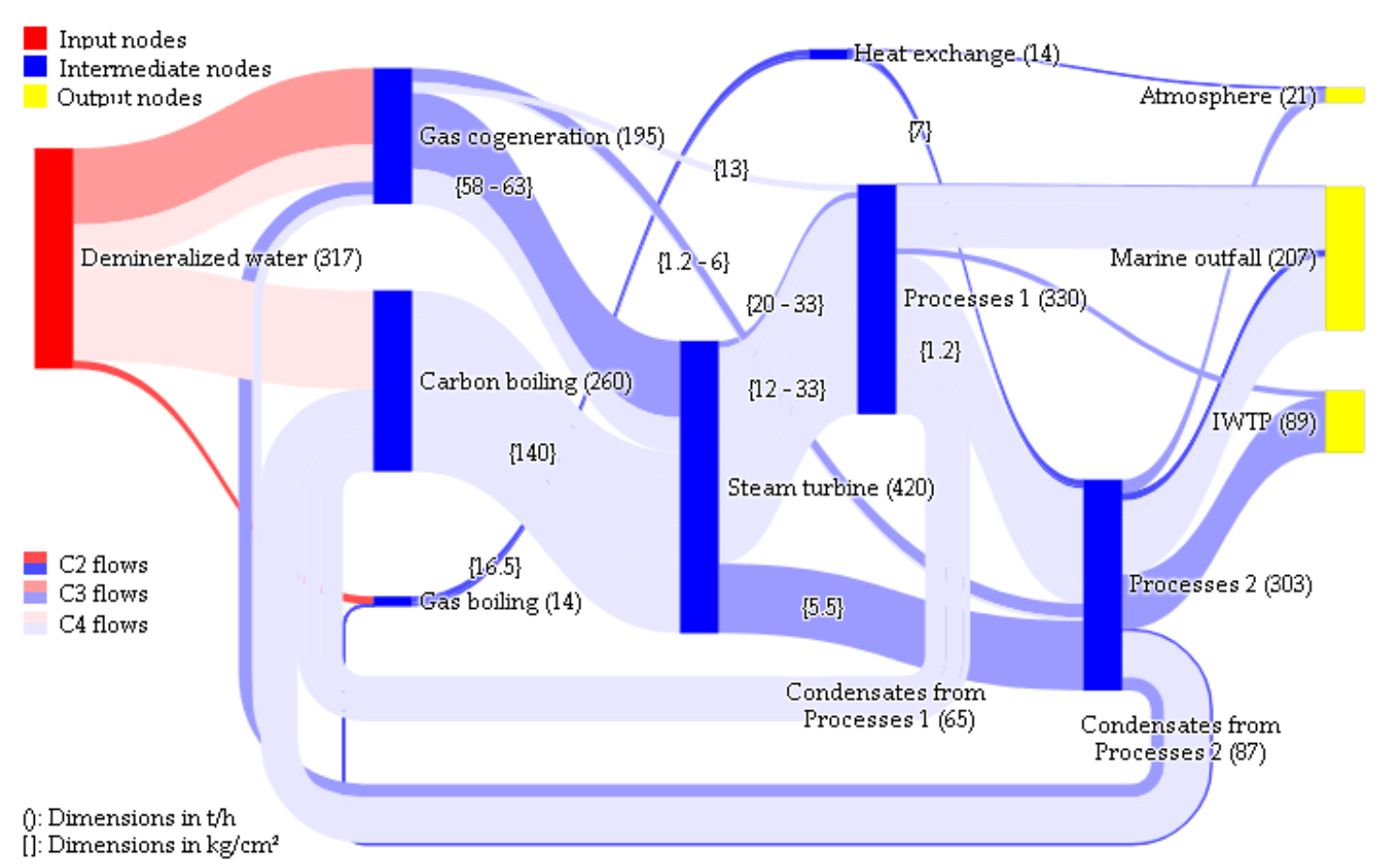

Figure 4. Sankey diagram of steam flows in the industrial park.

To quantify all these stages, Table 2 collects the path followed by steam in the companies that consumed it (C1's was a dry process), including those nodes involving production, pressure drops and consumption. Carbon was used only by $\mathrm{C} 4$, which also produced steam through cogeneration. This system was also used by $\mathrm{C} 3$, whilst $\mathrm{C} 2$ resorted to a gas boiler to generate steam. Table 2 specifies the amount of steam generated by each company using these systems, as well as their corresponding values of pressure. Once produced, high-pressure steam $\left(>35 \mathrm{~kg} / \mathrm{cm}^{2}\right)$ derived from carbon boiling and cogeneration in C3 and C4 was turbined in steam turbines at a medium $\left(8-35 \mathrm{~kg} / \mathrm{cm}^{2}\right)$ and low pressure $\left(<8 \mathrm{~kg} / \mathrm{cm}^{2}\right)$, respectively (Table 2). Similarly, the flow generated in $\mathrm{C} 2$ through gas boiling was laminated at a medium and low pressure through heat contact and exchange, as indicated in Table 2. To support the consideration of potential synergies based on this scheme, Table 3 summarizes the situation of the companies involved in the steam flow in what concerns their use, capacity, needs and margin.

In addition, Table 2 also indicates the role played by steam at the scale of the whole system, specifying the electric production and consumption patterns of the companies. In this sense, the sole purpose sought by $\mathrm{C} 2$ with respect to its steam production was its subsequent consumption in processes associated with this flow. Thus, all the electricity consumed by this company (30,600 MWh/yr.) was supplied by the national electrical grid. Instead, C3 devoted part of its steam production to electric energy. This company sold the energy produced in its cogeneration system $(719,300 \mathrm{MWh} / \mathrm{yr}$.) to the national electrical grid, whilst the portion of high-pressure steam produced through steam turbines $(81,600 \mathrm{MWh} / \mathrm{yr}$.) was used for the generation of electric energy for self-consumption. The origin of $\mathrm{C} 4$ electricity stemmed from turbined steam derived from carbon boiling (208,139 MWh/yr.) and the national electrical grid (125,308 MWh/yr.). 
Most of this electricity ended up being consumed in the processes (268,718 MWh/yr.), while a smaller part was returned to the national electrical grid (64,729 MWh/yr.).

Table 2. Scheme of the path followed by steam in the companies forming the industrial park.

\begin{tabular}{|c|c|c|c|c|c|c|c|c|c|}
\hline \multirow[t]{2}{*}{ ID } & \multirow[t]{2}{*}{ Flow } & \multicolumn{2}{|l|}{ Production } & \multicolumn{2}{|c|}{ Pressure drop 1} & \multicolumn{2}{|c|}{ Pressure drop 2} & \multicolumn{2}{|c|}{ Consumption } \\
\hline & & System & Amount* & Node & Amount* & Node & Amount* & System & Amount \\
\hline \multirow[b]{2}{*}{$\mathrm{C} 2$} & Steam & Gas boiling & $14\{16.5\}$ & Heat exchange & $14\{7\}$ & - & - & Processes 2 & 13 \\
\hline & Electricity & $\begin{array}{c}\text { National } \\
\text { electrical grid }\end{array}$ & 30,600 & - & - & - & - & Processes & 30,600 \\
\hline \multirow{6}{*}{$\mathrm{C} 3$} & Steam & \multirow{4}{*}{ Gas cogeneration } & $110\{63\}$ & \multirow{3}{*}{ Steam turbine } & $6\{33\}$ & - & - & \multirow[t]{4}{*}{ Processes 2} & \multirow[t]{4}{*}{130} \\
\hline & & & & & $4\{20\}$ & - & - & & \\
\hline & & & & & $100\{5.5\}$ & - & - & & \\
\hline & & & $20\{6\}$ & - & - & - & - & & \\
\hline & \multirow[t]{2}{*}{ Electricity } & \multirow[t]{2}{*}{ Gas cogeneration } & \multirow[t]{2}{*}{719,300} & - & - & - & - & \multirow{2}{*}{$\begin{array}{l}\text { National } \\
\text { electrical grid } \\
\text { Processes }\end{array}$} & 719,300 \\
\hline & & & & Steam turbine ${ }^{* *}$ & 81,600 & - & - & & 81,600 \\
\hline \multirow{9}{*}{$\mathrm{C} 4$} & \multirow{6}{*}{ Steam } & \multirow{3}{*}{ Gas cogeneration } & $50\{58\}$ & \multirow{6}{*}{$\begin{array}{c}\text { Steam turbine } \\
\text { Processes } 1 \\
- \\
\text { Steam turbine }\end{array}$} & $50\{13\}$ & - & - & Processes 2 & 50 \\
\hline & & & $10\{13\}$ & & $10\{1.2\}$ & - & - & Processes 2 & 10 \\
\hline & & & $5\{1.2\}$ & & - & - & - & Processes 2 & 5 \\
\hline & & \multirow[t]{3}{*}{ Carbon boiling } & \multirow[t]{3}{*}{$260\{140\}$} & & \multirow{3}{*}{$\begin{array}{c}50\{33\} \\
210\{13\}\end{array}$} & \multirow{3}{*}{$\begin{array}{c}- \\
\text { Processes } 1\end{array}$} & \multirow{3}{*}{$\begin{array}{c}- \\
155\{1.2\}\end{array}$} & Processes 2 & 50 \\
\hline & & & & & & & & Processes 2 & 155 \\
\hline & & & & & & & & Processes 2 & 55 \\
\hline & \multirow[t]{3}{*}{ Electricity } & Gas cogeneration & NA & \multirow{3}{*}{ Steam turbine ${ }^{* * *}$} & \multirow{3}{*}{208,139} & & & Private company & NA \\
\hline & & Carbon boiling & & & & & & Processes & 268,718 \\
\hline & & $\begin{array}{c}\text { National } \\
\text { electrical grid }\end{array}$ & 125,308 & & & & & $\begin{array}{c}\text { National } \\
\text { electrical grid }\end{array}$ & 64,729 \\
\hline
\end{tabular}

* Values in $\mathrm{t} / \mathrm{h}$ (pressure in $\mathrm{kg} / \mathrm{cm}^{2}$ ); ${ }^{* *}$ From gas cogeneration; ${ }^{* * *}$ From carbon boiling.

Table 3. Situation of steam flow use, capacity, needs and margin in the companies forming the industrial park.

\begin{tabular}{|c|c|c|c|c|c|c|c|c|}
\hline ID & System & Status & $\begin{array}{l}\text { Pressure } \\
\left(\mathrm{kg} / \mathrm{cm}^{2}\right)\end{array}$ & $\begin{array}{l}\text { Use } \\
(t / h)\end{array}$ & $\begin{array}{c}\text { Nominal } \\
\text { Capacity }(\mathrm{t} / \mathrm{h})\end{array}$ & $\begin{array}{c}\text { Needs } \\
(\%)\end{array}$ & $\begin{array}{c}\text { Availab } \\
(\%)\end{array}$ & $\underset{(t / h)}{\text { Margin }}$ \\
\hline \multirow{4}{*}{$\mathrm{C} 2$} & Global & Installed & - & 14 & 65 & 21 & 79 & 51 \\
\hline & \multirow[t]{2}{*}{ Production } & Active * & 16.5 & 14 & 40 & 35 & 65 & 26 \\
\hline & & Backup ** & 16.5 & 0 & 25 & 0 & 100 & 25 \\
\hline & Pressure drops & Active ${ }^{* * *}$ & 7 & 14 & 40 & 35 & 65 & 26 \\
\hline \multirow{7}{*}{$\mathrm{C} 3$} & Global & Installed & - & 130 & 295 & 44 & 56 & 165 \\
\hline & \multirow{3}{*}{ Production } & Active* & 63 & 110 & 125 & 88 & 12 & 15 \\
\hline & & & 6 & 20 & 35 & 57 & 43 & 15 \\
\hline & & Backup ** & 63 & 0 & 150 & 0 & 100 & 150 \\
\hline & \multirow[t]{3}{*}{ Pressure drops } & & 33 & 6 & 21 & 28 & 72 & 15 \\
\hline & & Active *** & 20 & 4 & 19 & 21 & 79 & 15 \\
\hline & & & 5.5 & 100 & 115 & 87 & 13 & 15 \\
\hline \multirow{10}{*}{$\mathrm{C} 4$} & \multirow[t]{2}{*}{ Global } & Installed & - & 325 & 530 & 61 & 39 & 205 \\
\hline & & Active* & 140 & 260 & 270 & 96 & 4 & 10 \\
\hline & \multirow{3}{*}{ Production } & & 58 & 50 & 60 & 83 & 17 & 10 \\
\hline & & & 13 & 10 & 20 & 50 & 50 & 10 \\
\hline & & & 1.2 & 5 & 15 & 33 & 67 & 10 \\
\hline & \multirow{5}{*}{ Pressure drops } & Backup ** & 58 & 0 & 185 & 0 & 100 & 185 \\
\hline & & \multirow{3}{*}{ Active $* * *$} & 33 & 50 & 60 & 83 & 17 & 10 \\
\hline & & & 13 & 270 & 290 & 93 & 7 & 20 \\
\hline & & & 1.2 & 170 & 190 & 89 & 11 & 20 \\
\hline & & Backup **** & 13 & 0 & 185 & 0 & 100 & 185 \\
\hline
\end{tabular}

* C2: Gas boiling; C3: Gas cogeneration; C4: Gas cogeneration $\left(140 \mathrm{~kg} / \mathrm{cm}^{2}\right)$ and Carbon boiling $\left(58 / 13 / 1.2 \mathrm{~kg} / \mathrm{cm}^{2}\right)$;

** C2: Backup gas boiling; C3: Backup carbon boiling; C4: Backup gas boiling *** C2: Heat exchange; C3: Steam turbine; C4: Steam turbine $\left(33 / 13 \mathrm{~kg} / \mathrm{cm}^{2}\right)$ and Processes $1\left(1.2 \mathrm{~kg} / \mathrm{cm}^{2}\right) ;{ }^{* * * *} \mathrm{C} 4$ : Steam turbine.

\subsection{Direct Synergies}

Table 4 summarises the purpose, participating companies and characteristics (Ch.) of the proposed direct synergies, as well as their identification through a three character code indicating type (S-Substitution), resource (M-Materials; W-Water; S-Steam) and number. The amount of limestone waste (calcined $\mathrm{CaCO}_{3}$ ) generated by $\mathrm{C} 4$ is currently poured into the sea through marine outfall, since it is not harmful for the environment as long as long the spillage is restricted. This was a priority due to its great proportion in the 
wastes generated by C4 (99\%). C2 consumes this material as an additive in the production of tyres, whilst $\mathrm{C} 3$ uses dolomite that can be partially replaced by $\mathrm{CaCO}_{3}$ in the production of cellulose (SM1). According to the BAT (Best Available Techniques) documents [35], about $70 \%$ of dolomite might be substituted by $\mathrm{CaCO}_{3}$ (2650 t/yr.). Overall, the residual mass flow of $\mathrm{CaCO}_{3}$ produced by $\mathrm{C} 4(205,684 \mathrm{t} / \mathrm{yr}$.) would completely meet the demands of C2 and C3 (2826.4 t/yr.).

Table 4. Summary of direct synergies identified in the industrial park.

\begin{tabular}{|c|c|c|c|c|c|c|c|c|c|}
\hline ID & Purpose & Donor & & & & Recipient & & & \\
\hline & & Company & Type & Ch. $1 *$ & Ch. $2 * *$ & Company & Type & Ch. $1^{* * *}$ & Ch. $2^{* * * *}$ \\
\hline \multirow[t]{2}{*}{ SM1 } & \multirow[t]{2}{*}{$\begin{array}{c}\mathrm{CaCO}_{3} \\
\text { exploitation }\end{array}$} & \multirow[t]{2}{*}{$\mathrm{C} 4$} & \multirow[t]{2}{*}{$\begin{array}{l}\text { Calcined } \\
\mathrm{CaCO}_{3}\end{array}$} & \multirow[t]{2}{*}{205,684} & \multirow[t]{2}{*}{ Suspended } & $\mathrm{C} 2$ & $\mathrm{CaCO}_{3}$ & 176.4 & Powder \\
\hline & & & & & & $\mathrm{C} 3$ & Dolomite & 2650 & Solid \\
\hline \multirow[t]{2}{*}{ SM2 } & \multirow[t]{2}{*}{$\begin{array}{c}\mathrm{CO}_{2} \\
\text { distribution }\end{array}$} & $\mathrm{C} 1$ & $\begin{array}{l}\mathrm{CO}_{2} \text { (VOCs } \\
\text { combustion) }\end{array}$ & 435 & $\begin{array}{l}\text { Adequate } \\
\text { quality }\end{array}$ & $\mathrm{C} 4$ & $\begin{array}{c}\mathrm{CO}_{2} \\
\text { (limestone \& } \\
\text { anthracite } \\
\text { calcination) }\end{array}$ & 666,000 & $95 \%$ pure \\
\hline & & $\mathrm{C} 2$ & $\begin{array}{l}\mathrm{CO}_{2} \text { (VOCs } \\
\text { combustion) }\end{array}$ & NA & $\begin{array}{l}\text { Adequate } \\
\text { quality }\end{array}$ & & & & \\
\hline SM3 & $\begin{array}{c}\text { Oil } \\
\text { exploitation }\end{array}$ & $\mathrm{C} 2$ & Oil & 20.7 & $\begin{array}{l}\text { Used as a } \\
\text { lubricant }\end{array}$ & $\mathrm{C} 1$ & Reused oil & $\mathrm{NA}^{* * * * *}$ & $\begin{array}{l}\text { Impurities } \\
\text { are allowed }\end{array}$ \\
\hline SM4 & $\begin{array}{c}\text { Brine } \\
\text { exploitation }\end{array}$ & $\mathrm{C} 4$ & Used brine & 110,000 & NA & C3 & Brine & 8965 & $\begin{array}{l}\text { Low salt. } \\
\text { Mercury }\end{array}$ \\
\hline SW2 & $\begin{array}{c}\text { Purified } \\
\text { water reuse }\end{array}$ & $\mathrm{C} 3$ & $\begin{array}{c}\text { IWTP } \\
\text { (purified } \\
\text { water) }\end{array}$ & 1230 & $\begin{array}{l}\text { Suspended } \\
\text { solids }\end{array}$ & $\mathrm{C} 1$ & $\begin{array}{l}\text { Well (raw } \\
\text { water) }\end{array}$ & 8 & $\begin{array}{l}<5 \mathrm{mg} / \mathrm{L} \\
\text { suspended } \\
\text { solids }\end{array}$ \\
\hline SW3 & $\begin{array}{l}\text { Rainwater } \\
\text { reuse }\end{array}$ & $\mathrm{C} 3$ & Rainwater & 200 & $\begin{array}{l}\text { Suspended } \\
\text { solids }\end{array}$ & $\mathrm{C} 4$ & $\begin{array}{l}\text { River (filtered } \\
\text { water) }\end{array}$ & 993 & $\begin{array}{l}<35 \mathrm{mg} / \mathrm{L} \\
\text { suspended } \\
\text { solids }\end{array}$ \\
\hline SW4 & $\begin{array}{c}\text { Purified } \\
\text { water reuse }\end{array}$ & $\mathrm{C} 4$ & $\begin{array}{c}\text { IWTP } \\
\text { (purified } \\
\text { water) }\end{array}$ & 604 & $\begin{array}{l}\text { Mercury } \\
\left(5 \times 10^{-5}\right. \\
\text { ppm })\end{array}$ & $\mathrm{C} 3$ & $\begin{array}{l}\text { River (raw } \\
\text { water) }\end{array}$ & NA & $\begin{array}{c}<5 \times 10^{-5} \\
\text { ppm mercury }\end{array}$ \\
\hline SS1 & $\begin{array}{l}\text { Unrecovered } \\
\text { steam reuse }\end{array}$ & $\mathrm{C} 3$ & Waste steam & NA & NA & $\mathrm{C} 1$ & Hot steam & 150 & $95^{\circ} \mathrm{C}$ \\
\hline
\end{tabular}

* Amount in t/yr. (SM1-SM4)/Amount in $\mathrm{m}^{3} / \mathrm{h}$ (SW1-SS1); ${ }^{* *}$ Qualitative feature (SM1-SM4, SS1)/Outflow condition (SW1-SW4); ${ }^{* * *}$ Amount in t/yr. (SM1-SM4)/Amount in $\mathrm{m}^{3} / \mathrm{h}$ (SW1-SW4, SS1); ${ }^{* * * *}$ Qualitative feature (SM1-SM4); Limit values for water reuse (SW1-SW4); Temperature in ${ }^{\circ} \mathrm{C}(\mathrm{SS} 1) ;{ }^{* * * *} \mathrm{NA}$ : not specified.

Both $\mathrm{C} 2$ and $\mathrm{C} 1$ generate controlled $\mathrm{CO}_{2}$ emissions through Regenerative Thermal Oxidizers (RTO) for Volatile Organic Compounds (VOCs) that may fit the interests of C4 (SM2). Along with calcium oxide $(\mathrm{CaO}), \mathrm{CO}_{2}$ was the main compound of $\mathrm{CaCO}_{3}$ calcination, which is a reactant involved in $\mathrm{C}^{\prime}$ 's main chemical process for manufacturing sodium carbonate. However, $\mathrm{C} 4$ was found to have no $\mathrm{CO}_{2}$ deficit, to the extent that part of its $\mathrm{CO}_{2}$ exceeded the amount necessary for the reaction and was released to the atmosphere. Hence, a complementary option may consist of creating some infrastructure for capturing the $\mathrm{CO}_{2}$ emissions produced by all these companies.

In a similar vein, $\mathrm{C} 1$ consumes oil previously used in its own combustion engines for subsequent reuse in the removal of polyethylene pigments. Consequently, this company has no deficit either, thereby not requiring the oil produced by $\mathrm{C} 2$ (SM3). C4 generates brine waste from electrolysis processes with an initial concentration of $250 \mathrm{~g} / \mathrm{kg}$ of $\mathrm{NaCl}$. Then, this flow is purified in the IWTP to reduce the amount of mercury to the allowed limits. Although C3 consumes brine in its production processes, the characteristics of this waste should be analysed more in detail to guarantee the compatibility of this synergy (SM4).

Two potential synergies (SW1 and SW2) were identified to reuse water from C3 IWTP in C4 and C1. The amount of suspended solids in the IWTP would not be a problem, since it is within the limits to reuse water for industrial purposes. Therefore, it might be used by $\mathrm{C} 4$, since most of its consumption is filtered water from a river, whose quality requirements meet those of the IWTP outflow. On the contrary, the amount of suspended solids in C3 water exceeds that of the raw water collected from the 
well by $\mathrm{C} 1$. Although $\mathrm{C} 1$ facilities have the capacity for reducing dissolved solids, chlorine and organic matter, this treatment would produce new wastes that were not previously generated by this company.

The collection of rainwater in $\mathrm{C} 3$ is discharged into the river. Thus, its reuse by $\mathrm{C} 4$ as filtered or raw water (SW3) would require some treatment to ensure it meets current standards of quality [36]. Furthermore, since most of the water consumed by $\mathrm{C} 4$ is filtered, rainwater could be recirculated and reused to moisten ashes in generators and refrigerate the electrolysis unit.

Some of the processes carried out by C3 do not require high quality water, such as wood barking. Hence, wastewater from C4 might be used as a replacement in these situations (SW4), since its mercury contents meet the standards of environmental quality [37]. However, C3 water supply is undertaken through a pressurized circuit, whose flexibility should be studied to evaluate more in depth the suitability of this synergy. Additionally, it is also necessary to detail the use and conditions of water quality in C3 to assess the adequacy of this substitution.

The steam-related direct synergy (SS1) involved reusing non-recovered steam from C3 in C1. Hot water consumption in $\mathrm{C} 1$ was carried out at $95^{\circ} \mathrm{C}$; however, there was no certainty about whether this temperature may be reached by some non-recovered steam flow from C3. Hence, although this substitution might be potentially feasible, the lack of data regarding the flow and characteristics of non-recovered steam in C3 precluded its implementation (Table 4).

\subsection{Indirect Synergies}

Table 5 is analogous to Table 4 but applies to the indirect synergies identified, such that the first character in their codification denotes mutuality (M). The analysis of auxiliary material consumption in the industrial park revealed that some companies shared input flows. In particular, C3 and C4 were found to consume brine in their respective production processes. Hence, improvements in economies of scale might be obtained in case both companies had the same brine supplier (MM1). Since C4 is self-dependent in the extraction of brine from salt surveys, it may directly supply $\mathrm{C} 3$, whose stock stems from a company belonging to the same corporate group.

In the same vein, there were a list of synergies based on sharing the same supplier of auxiliary production services (MM2). These implementations would not only yield economic improvements, but also environmental benefits in distribution logistics. The role played by $\mathrm{C} 4$ was particularly relevant in this synergy, since it owns the facilities required to provide $\mathrm{C} 1$ with hypochlorite and $\mathrm{C} 1-\mathrm{C} 2-\mathrm{C} 3$ with hydrochloric acid, chlorine (own internal generation) and caustic soda. Data availability hindered the proposal of specific actions for other cases involving aluminum polychloride, oxygen and hydraulic oils, which were limited in providing details about suppliers and/or amounts.

The common storage of these same auxiliary production services (MM3) would result in the optimization of logistics, since the supply of materials would be limited to only one location, and an increase in room availability. C4 proved to be capable of storing the whole amount of hypochlorite, hydrochloric acid and hydraulics oils in the industrial park. C2 was found to have space for storing hydraulic oils too, as well as oxygen. Caustic soda was storable by $\mathrm{C} 3$ and C4, whilst data scarcity precluded determining the situation of aluminium polychloride.

MM4 and MM5 sought to produce economic and environmental gains in the industrial park by jointly managing both hazardous and non-hazardous wastes. $\mathrm{C} 1$ was the company producing a wider variety of shared wastes ( 8 hazardous and 6 non-hazardous), followed by C3 (4 hazardous and 6 non-hazardous) and both C2 (6 hazardous and 3 non-hazardous) and C4 (9 hazardous). C4 was the greater contributor to generating hazardous wastes with the potential for cooperation (MM4), especially with regards to the amount produced ( $82.3 \mathrm{t} / \mathrm{yr}$.), followed by C1 (67.8t/yr.), C3 (38.7 t/yr.) and C2 (37.7 t/yr.). Used oils (81.1 t/yr.) and plastic and metal containers (73.2 t/yr.) were the most shared hazardous waste in the industrial park. The same external company was in charge of the free pickup of used oils for C1, C2 and C4; instead, this information was unspecified for C3. The remaining 8 shared hazardous wastes (Table 5) were handled by different external managers (unknown in some cases). Therefore, an improvement may consist of homogenizing the management of these 
wastes and reducing the number of external companies involved. However, this option should be considered carefully, since it may eventually lead to a monopolistic situation characterized by rising collection prices.

Table 5. Summary of indirect synergies identified in the industrial park.

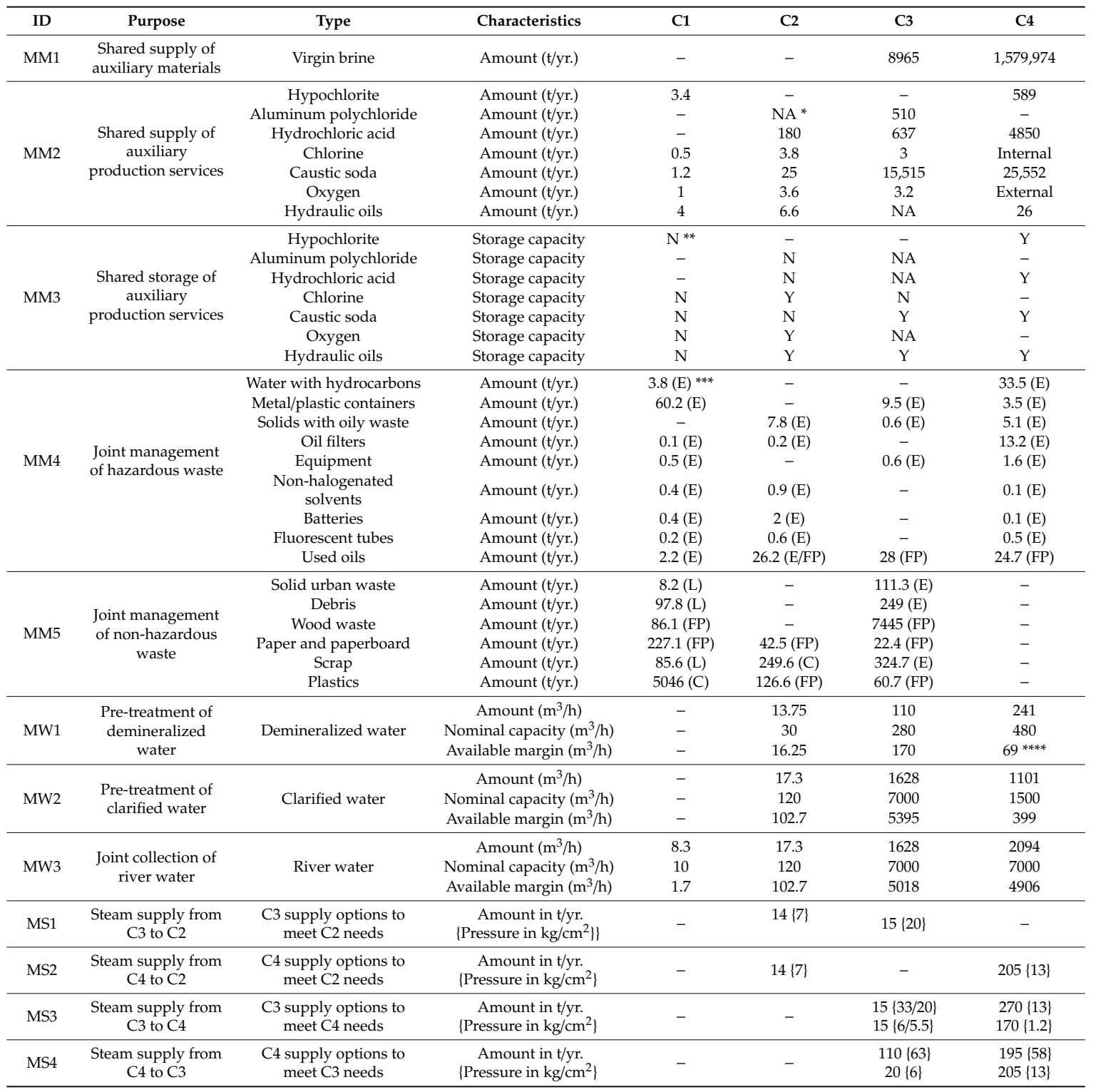

${ }^{*} \mathrm{NA}$ : not specified; ${ }^{* *} \mathrm{~N}$ : there is not enough capacity to store the flow of auxiliary production services/Y: there is enough capacity to store the flow of auxiliary production services; ${ }^{* * *} \mathrm{E}$ : external management/FP: free pickup/C: sale to company/L: landfill; ${ }^{* * *}$ restricted capacity due to the decarbonation step previous to water demineralization.

The management of non-hazardous wastes (MM5) was even more difficult to characterize due to the lack of detailed data. C3 was the main producer of non-hazardous wastes suitable for synergies, generating $8213 \mathrm{t} / \mathrm{yr}$. C1 and C2 were responsible for 5524 and $419 \mathrm{t} / \mathrm{yr}$., respectively. Although C4 produced 205,715.9 t/yr. (mostly calcined calcium carbonate), none of its residues were suitable for sharing. In those cases in which the same approach was used to manage waste (wood, scrap and paper and paperboard), there was at least one company that did not provide any details about the destination of either their companies or landfills. Potential alternatives to better handle hazardous wastes might focus on the coordination of their management methods, such that transportation costs and emissions may be reduced. These actions should be especially oriented to wood waste (7531 t/yr.) 
and plastics (5233 t/yr.), which were the shared non-hazardous waste generated in a greater quantity in the industrial park.

Two of the three water-related synergies consisted of the pretreatment of either demineralized (MW1) or clarified water (MW2). The use of demineralized water was common for C2, C3 and C4. Both C3 and C4 had the capacity for supplying the needs of C2 $\left(13.75 \mathrm{~m}^{3} / \mathrm{h}\right)$. Water in C4 went through previous treatments before demineralization, whereby the amount available was reduced to $69 \mathrm{~m}^{3} / \mathrm{h}$, which would only cover 55.25 of the $110 \mathrm{~m}^{3} / \mathrm{h}$ required by C3 (50.23\%). Instead, this figure increased up to $64.73 \%$ (156 of $241 \mathrm{~m}^{3} / \mathrm{h}$ ) when the supply was from C3 to C4. Similarly, C3 was found to be capable of supplying C2 $\left(17.3 \mathrm{~m}^{3} / \mathrm{h}\right)$ and $\mathrm{C} 4\left(1101 \mathrm{~m}^{3} / \mathrm{h}\right)$ in terms of clarified water (MW2), due to its $77 \%$ available margin $\left(5390 \mathrm{~m}^{3} / \mathrm{h}\right)$. Finally, the last water synergy (MW3) concerned the collection of river water from the same point. In this case, three companies (C2-C4) collected river water, whilst $\mathrm{C} 1$ used water of similar quality from a well. Therefore, this synergy would involve C1 replacing well water by river water from a common collection point, in order to obtain economic savings in terms of collection fees.

The remaining indirect synergies consisted of the supply of high and medium pressure steam from one company to another. To enable these types of synergies, the companies involved must meet certain conditions. First, recipient companies should be inefficient in terms of steam use with respect to their nominal capacity; otherwise, the supply of steam from another company might not be beneficial at the scale of the whole industrial park. Additionally, recipient companies should have steam needs that were replaceable without compromising its linkage to the generation of electric energy. From the point of view of suppliers, they must have the available margin to provide recipients with steam. In addition, the levels of pressure at which such margin was available should not involve large leaps with respect to the uses of recipient companies, in order to make optimal use of steam.

The first opportunity identified concerned the supply from either $\mathrm{C} 3$ or $\mathrm{C} 4$ to $\mathrm{C} 2$, since the latter was found to be very inefficient in using steam. It only used $21 \%$ of its nominal capacity (Table 3 ) and operated under a discontinuous working regime with weekly breaks, whereby a synergy for the steam supply to $\mathrm{C} 2$ might increase the productivity in the industrial park. C2 was also suitable in terms of electricity, since its production was null in this sense (Table 2) and a potential steam-related synergy would not interfere in its energy flow. C2 needs included the production of $14 \mathrm{t} / \mathrm{h}$ at $16.5 \mathrm{~kg} / \mathrm{cm}^{2}$ to be used for heat exchange at $7 \mathrm{~kg} / \mathrm{cm}^{2}$, as represented in Tables 5 and 6 .

MS1 involved C3 as a supplier, which had $56 \%$ of the margin with respect to its nominal capacity to supply C2. Due to the values of pressure at which flow was available in C3 (Tables 5 and 6), the first option would consist of supplying $14 \mathrm{t} / \mathrm{h}$ at $63 \mathrm{~kg} / \mathrm{cm}^{2}$ to be used at $7 \mathrm{~kg} / \mathrm{cm}^{2}$; however, this was discarded too due to the large pressure difference it involved. Instead, C3 may shorten that leap by supplying the $14 \mathrm{t} / \mathrm{h}$ required by $\mathrm{C} 2$ at $20 \mathrm{~kg} / \mathrm{cm}^{2}$, once the steam produced through cogeneration was turbined (Table 3).

In the case of MS2, the options were rather similar. The margin available in C4 was 39\% of its nominal capacity (Table 3). Again, the pressure drops caused by turbines made available $10 \mathrm{t} / \mathrm{h}$ at $33 \mathrm{~kg} / \mathrm{cm}^{2}$ and $205 \mathrm{t} / \mathrm{h}$ at $13 \mathrm{~kg} / \mathrm{cm}^{2}$ that would be sufficient to cover C2's requirements. Thus, C2 may use $14 \mathrm{t} / \mathrm{h}$ at $13 \mathrm{~kg} / \mathrm{cm}^{2}$ to replace C2 uses at $7 \mathrm{~kg} / \mathrm{cm}^{2}$.

The two remaining synergies implied the supply from C3 to C4 (MS3), and vice versa (MS4). Again, the aim of these synergies was to improve the efficiency of the suppliers and reduce the equipment used by the recipient companies. In this sense, both companies proved to be more efficient than C2. C4 was found to operate at $61 \%$ of their nominal capacity, whilst this figure decreased to $44 \%$ in the case of C3 (Table 3).

The applicability of MS3 would be limited to supply part of the uses derived from C4 carbon boiling, since the flow generated by $\mathrm{C} 4$ through cogeneration was linked to the sale of electricity to a private company (Table 2). Since the steam produced in $\mathrm{C} 4$ through carbon boiling was at a much higher pressure $\left(140 \mathrm{~kg} / \mathrm{cm}^{2}\right)$ than any flow available in C3 (Table 3), the feasible options associated with MS3 were restricted to subsequent lamination steps (Table 5). Hence, C3 may substitute part of 
C4 uses at 33, 13 and $1.2 \mathrm{~kg} / \mathrm{cm}^{2}$ through the supply of flow at 33,20 and $6 / 5.5 \mathrm{~kg} / \mathrm{cm}^{2}$, respectively, as collected in Table 3.

Table 6. Sustainable Development Goals (SDGs) and targets to which the selected Industrial Symbiosis (IS) synergies can contribute.

\begin{tabular}{|c|c|}
\hline SDG & Target \\
\hline 3. Good health and well-being & $\begin{array}{c}\text { 3.9. By 2030, }[\ldots] \text { reduce }[\ldots] \text { deaths and illnesses from hazardous chemicals } \\
\text { and air, water and soil pollution }[\ldots]\end{array}$ \\
\hline \multirow{2}{*}{ 6. Clean water and sanitation } & $\begin{array}{l}\text { 6.3. By 2030, improve water quality by reducing pollution, eliminating dumping } \\
\text { and minimizing }[\ldots] \text { hazardous chemicals and materials }[\ldots]\end{array}$ \\
\hline & $\begin{array}{l}\text { 6.4. By 2030, [... ] increase water-use efficiency across all sectors and ensure } \\
\text { sustainable withdrawals and supply of freshwater }[\ldots]\end{array}$ \\
\hline 7. Affordable and clean energy & 7.3. By 2030, double the global rate of improvement in energy efficiency \\
\hline 8. Decent work and economic growth & $\begin{array}{l}\text { 8.4. Improve }[\ldots] \text { resource efficiency in consumption and production and }[\ldots] \\
\text { decouple economic growth from environmental degradation }[\ldots]\end{array}$ \\
\hline 9. Industry, innovation and infrastructure & $\begin{array}{l}\text { 9.4. By } 2030,[\ldots] \text { retrofit industries to make them sustainable, with increased } \\
\text { resource-use efficiency and }[\ldots] \text { clean }[\ldots] \text { technologies }[\ldots]\end{array}$ \\
\hline 11. Sustainable cities and communities & $\begin{array}{l}\text { 11.6. By } 2030 \text {, reduce the }[\ldots] \text { environmental impact of cities }[\ldots] \text { by paying } \\
\text { special attention to air quality and }[\ldots \text { ] waste management }\end{array}$ \\
\hline \multirow{4}{*}{ 12. Responsible consumption and production } & $\begin{array}{c}\text { 12.2. By 2030, achieve the sustainable management and efficient use of } \\
\text { natural resources }\end{array}$ \\
\hline & $\begin{array}{l}\text { 12.4. By 2020, achieve the environmentally sound management of chemicals and } \\
\text { all wastes }[\ldots] \text { and }[\ldots] \text { reduce their release to air, water and soil }[\ldots]\end{array}$ \\
\hline & $\begin{array}{l}\text { 12.5. By 2030, substantially reduce waste generation through prevention, } \\
\text { reduction, recycling and reuse }\end{array}$ \\
\hline & $\begin{array}{l}\text { 12.6. Encourage companies, especially large and transnational companies, to } \\
\text { adopt sustainable practices and to integrate sustainability information }[\ldots]\end{array}$ \\
\hline 14. Life below water & $\begin{array}{l}\text { 14.1. By 2025, prevent and significantly reduce marine pollution of all kinds, } \\
\text { in particular from land-based activities [ ... ] }\end{array}$ \\
\hline \multirow[t]{2}{*}{ 17. Partnerships for the goals } & $\begin{array}{l}\text { 17.13. Enhance global macroeconomic stability, including through policy } \\
\text { coordination and policy coherence }\end{array}$ \\
\hline & 17.14. Enhance policy coherence for sustainable development \\
\hline
\end{tabular}

The viability of MS4 (from C4 to C3) was limited too, in this case by the double role played by the C3 turbine: it not only served to laminate steam, but also to generate the $81,600 \mathrm{MWh} / \mathrm{yr}$. that was consumed by this company in its own processes (Table 2). Taking into account this link with the electricity flow, the only feasible option in synergy MS4 was the supply of steam from C4 at 58 and $13 \mathrm{~kg} / \mathrm{cm}^{2}$ to replace the whole flows produced in C3 through gas cogeneration, which amounted to $110 \mathrm{t} / \mathrm{h}$ at $63 \mathrm{~kg} / \mathrm{cm}^{2}$ and $20 \mathrm{t} / \mathrm{h}$ at $6 \mathrm{~kg} / \mathrm{cm}^{2}$, respectively (Table 2).

\subsection{Implementation of Selected Synergies}

Figure 5 summarises the synergies selected for subsequent analyses, which were shortlisted because of their feasibility and potential benefits for the industrial park as a whole. Most of these synergies involved C3 and C4, which was logical due to the larger size and capacity of these two companies. Still, although some of the selected synergies might be feasible based on the information collected throughout the study, the existence of data for their numeric characterization was limited due to their especially indirect nature. This was the case of MM1, MM2, MM3, MM4, MM5 and MW3.

In the case of materials, both feasible and selected synergies coincided. This was because of the absence of overlaps, whereby the same synergy in conceptual terms might be posed using different companies as donors and/or recipients. Instead, the water-related synergies required selecting among different feasible options according to their potential positive impacts on the industrial park. This was the case of SW1, which was chosen over SW4 due to the larger capacity of C3 for supplying purified water meeting the required water quality standards for reuse. 


\begin{tabular}{|c|c|c|}
\hline \multicolumn{3}{|c|}{$\begin{array}{l}\text { Materials } \\
\text { - Water }\end{array}$} \\
\hline - Steam & $\begin{array}{l}\text { MM4 } \\
\text { MM5 }\end{array}$ & $\begin{array}{r}\text { MM4 } \\
\text { MM3 MM5 }\end{array}$ \\
\hline $\begin{array}{l}\text { MM4 } \\
\text { MM5 N }\end{array}$ & [M3 & MM3 MM4 \\
\hline \begin{tabular}{|l|} 
Synergy \\
\end{tabular} & Companies & Effect \\
\hline SM1 & $\mathrm{C} 4 \rightarrow \mathrm{C} 2, \mathrm{C} 3$ & $\begin{array}{l}\text {-176.4 t/yr. } \mathrm{CaCO}_{3}(\mathrm{C} 2) ;-2,650 \text { t/yr. dolomite }(\mathrm{C} 3) \\
-2,826.4 \text { t/yr. calcined } \mathrm{CaCO}_{3} \text { wasted }(\mathrm{C} 4)\end{array}$ \\
\hline SM4 & $\mathrm{C} 4 \rightarrow \mathrm{C} 3$ & $\begin{array}{l}-8,965 \mathrm{t} / \mathrm{yr} \text {. brine }(\mathrm{C} 3) \\
-8,965 \mathrm{t} / \mathrm{yr} \text {. used brine wasted }(\mathrm{C} 4)\end{array}$ \\
\hline MM1 & $\mathrm{C} 3, \mathrm{C} 4$ & Shared supply of brine \\
\hline MM2 & $\begin{array}{l}\mathrm{C} 1, \mathrm{C} 4 \\
\mathrm{C} 1, \mathrm{C} 2, \mathrm{C} 3, \mathrm{C} 4\end{array}$ & $\begin{array}{l}\text { Shared supply of hypochlorite } \\
\text { Shared supply of hypochloric acid, chlorine and caustic soda }\end{array}$ \\
\hline MM3 & $\begin{array}{l}\mathrm{C} 4 \\
\mathrm{C} 2 \\
\mathrm{C} 3, \mathrm{C} 4\end{array}$ & $\begin{array}{l}\text { Shared storage of hypochlorite, hydrochloric acid and hydraulic oils } \\
\text { Shared storage of hydraulic oils and oxygen } \\
\text { Shared storage of caustic soda }\end{array}$ \\
\hline MM4 & $\begin{array}{l}\mathrm{C} 1, \mathrm{C} 4 \\
\mathrm{C} 1, \mathrm{C} 3, \mathrm{C} 4 \\
\mathrm{C} 2, \mathrm{C} 3, \mathrm{C} 4 \\
\mathrm{C} 1, \mathrm{C} 2, \mathrm{C} 4\end{array}$ & $\begin{array}{l}\text { Joint management of water with hydrocarbons } \\
\text { Joint management of metal/plastic containers and equipment } \\
\text { Joint management of solids with oily waste and used oils } \\
\text { Joint management of oil filters, non-halogenated solvents, batteries } \\
\text { and fluorescent tubes }\end{array}$ \\
\hline MM5 & $\begin{array}{l}\mathrm{C} 1, \mathrm{C} 3 \\
\mathrm{C} 1, \mathrm{C} 2, \mathrm{C} 3 \\
\mathrm{C} 2, \mathrm{C} 3\end{array}$ & $\begin{array}{l}\text { Joint management of wood waste } \\
\text { Joint management of paper and paperboard } \\
\text { Joint management of plastics }\end{array}$ \\
\hline SW1 & $\mathrm{C} 3 \rightarrow \mathrm{C} 4$ & $-793 \mathrm{~m}^{3} / \mathrm{h}$ river water $(\mathrm{C} 4)$ \\
\hline SW3 & $\mathrm{C} 3 \rightarrow \mathrm{C} 4$ & $-200 \mathrm{~m}^{3} / \mathrm{h}$ river water $(\mathrm{C} 4)$ \\
\hline MW1 & $\mathrm{C} 3 \rightarrow \mathrm{C} 2, \mathrm{C} 4$ & -1 demineralizer $(\mathrm{C} 2)$ \\
\hline MW2 & $\mathrm{C} 3 \rightarrow \mathrm{C} 2, \mathrm{C} 4$ & -1 clarifier $(\mathrm{C} 2) ;-1$ clarifier $(\mathrm{C} 4)$ \\
\hline MW3 & $\mathrm{C} 1, \mathrm{C} 2, \mathrm{C} 3, \mathrm{C} 4$ & $-8 \mathrm{~m}^{3} / \mathrm{h}$ well water $(\mathrm{C} 1) ;+8 \mathrm{~m}^{3} / \mathrm{h}$ river water $(\mathrm{C} 1)$ \\
\hline MS2 & $\mathrm{C} 4 \rightarrow \mathrm{C} 2$ & -1 gas boiler $(\mathrm{C} 2)$ \\
\hline MS4 & $\mathrm{C} 4 \rightarrow \mathrm{C} 3$ & -1 gas cogeneration $(\mathrm{C} 3) ;+1$ backup gas boiler $(\mathrm{C} 4)$ \\
\hline
\end{tabular}

Figure 5. Summary of the selected synergies identified in the industrial park under study.

Similarly, C3 was found to be the best company to perform as a supplier of demineralized and clarified water (MW1 and MW2). Although both C3 and C4 could provide C2 with their needs in terms of demineralized water, their available margin to supply each other was larger if the synergy was posed from $\mathrm{C} 3$ to $\mathrm{C} 4$. In a similar vein, $\mathrm{C} 3$ proved to be capable of completely supplying both C2 and C4 with clarified water. Instead, C4 would only have capacity for supplying C2 and a small part of C3 needs. The remaining water-related synergies (SW3 and MW3) were only addressable in one manner, thereby not requiring any choice among companies.

The actions to be taken in the steam-related synergies were restricted by their potential impact on the energetic strategy of the companies. Under these two premises, the best combo of indirect synergies corresponded to MS2 and MS4 (Table 3). On the one hand, these two synergies involved the same supplier (C4) and made using two infrastructures in C2 and C3 unnecessary (Figure 5), thereby 
meeting the first criterion related to global efficiency. On the other hand, these synergies were also aligned with the requirement of not interfering in the electricity flow of the companies. C2 did not produce electricity through steam, whilst C 3 sold it to the national electrical grid. Thus, C3 was subject to the uncertainty of demand and supply, such that the productivity of its energy sales would not be solid enough as to discourage the implementation of synergies involving benefits at a larger scale.

Proposing C4 as a supplier was the best alternative, even when considering that part of its production stemmed from carbon boiling, which is environmentally harmful in terms of greenhouse gas emissions. In fact, MS2 and MS4 involved C4 backup gas boiler for supplying, thereby not contributing to carbon burning. In this vein, the alternative of using $\mathrm{C} 3$ as a supplier would not cause a significant variation in $\mathrm{C} 4$ carbon-related production, since only a small part of the steam required by C4 could be supplied through MS3 (Table 5).

Hence, with respect to the diagrams in Figure 2, the consideration of the selected materials synergies only affected three groups: auxiliary materials, non-hazardous wastes and emissions and discharges. SM1 and SM4 were responsible for these changes, whereby both brine and calcium carbonate wastes were recirculated from some companies for reuse as auxiliary materials in others (Figure 5). As a result, the auxiliary materials' bars representing brine and calcium carbonate production in Figure 6 were reduced to zero, whilst that corresponding to dolomite was shortened by $70 \%$. Consistent with these changes, calcined calcium carbonate and brine non-hazardous wastes and discharges were diminished too.
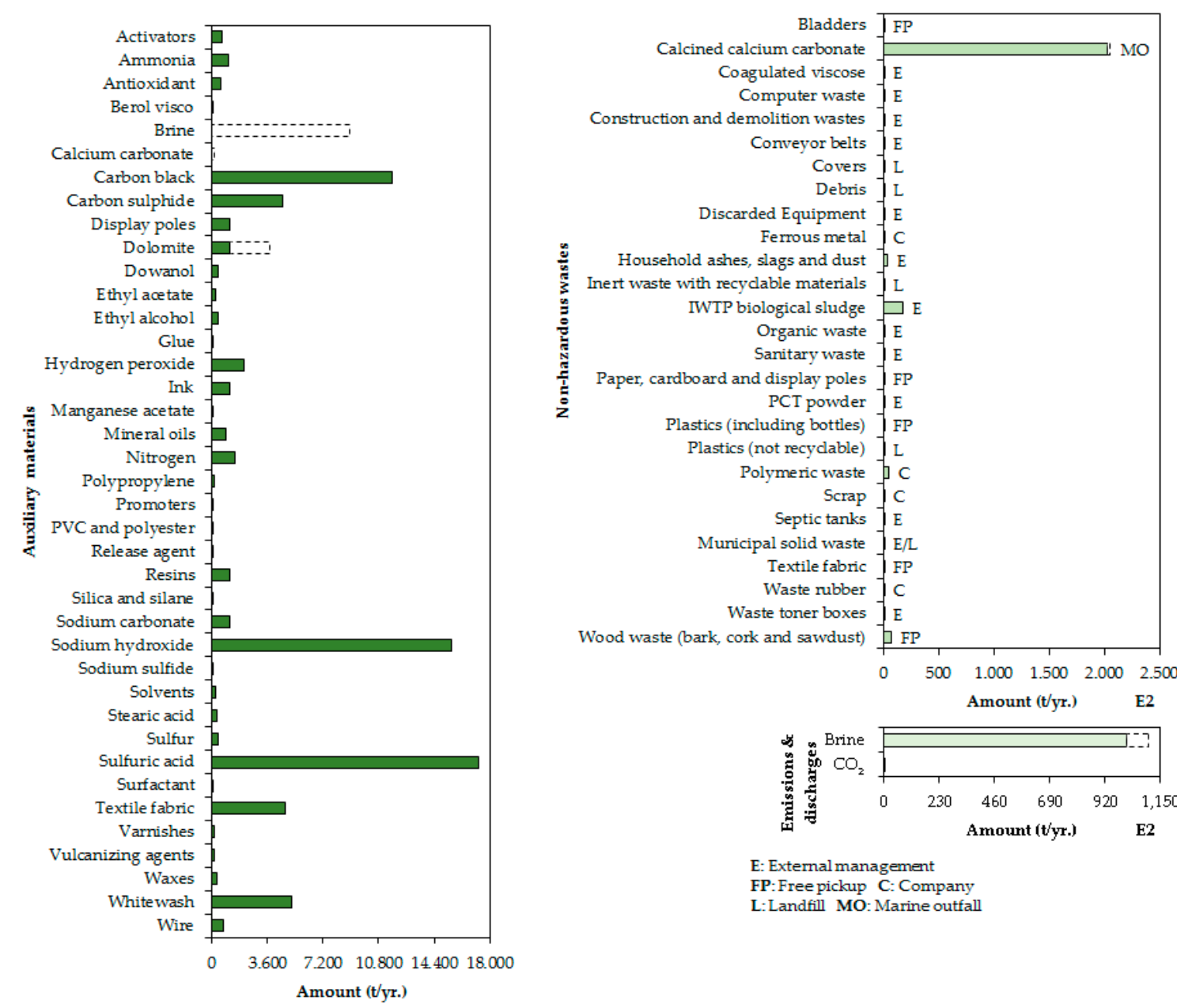

E: External management

FP: Freepickup C: Company

L: Landfill MO: Marine outfall

Figure 6. Breakdown of materials and wastes in the industrial park after implementing the synergies.

The remaining cooperation opportunities identified in Table 5 (MM1-MM5) consisted of either the shared use of supply or storage facilities for auxiliary production services or the joint management of hazardous and non-hazardous wastes, which had no visual repercussion on the charts included in 
Figure 2. Although no data were found to quantify the contribution of these synergies, they would produce positive impacts on the economic and environmental response of the park, optimizing its performance by improving its logistics through the centralization of materials flows, as well as by increasing its spatial availability in anticipation of potential future expansions.

Figure 7 depicts the evolution of the Sankey diagram for water flows once the synergies proposed in Figure 5 were implemented. Direct synergies SW1 and SW3 enabled a reduction of 793 and $200 \mathrm{~m}^{3} / \mathrm{h}$ in the amount of river water required in the industrial park, respectively. Both synergies involved C4 as a recipient, whose river water flow was completely directed to the coarse filtering node. Since the water quality associated with these synergies was equivalent to that of filtered water, rainwater and IWTP changed their previous roles, whereby the former flowed to marine outfall and the latter was an output node exclusively, to flow to the clarification node. Additionally, IWTP maintained its output role, whereby it received flows from the following nodes: cooling towers, toilets, processes, auxiliary systems and generation.

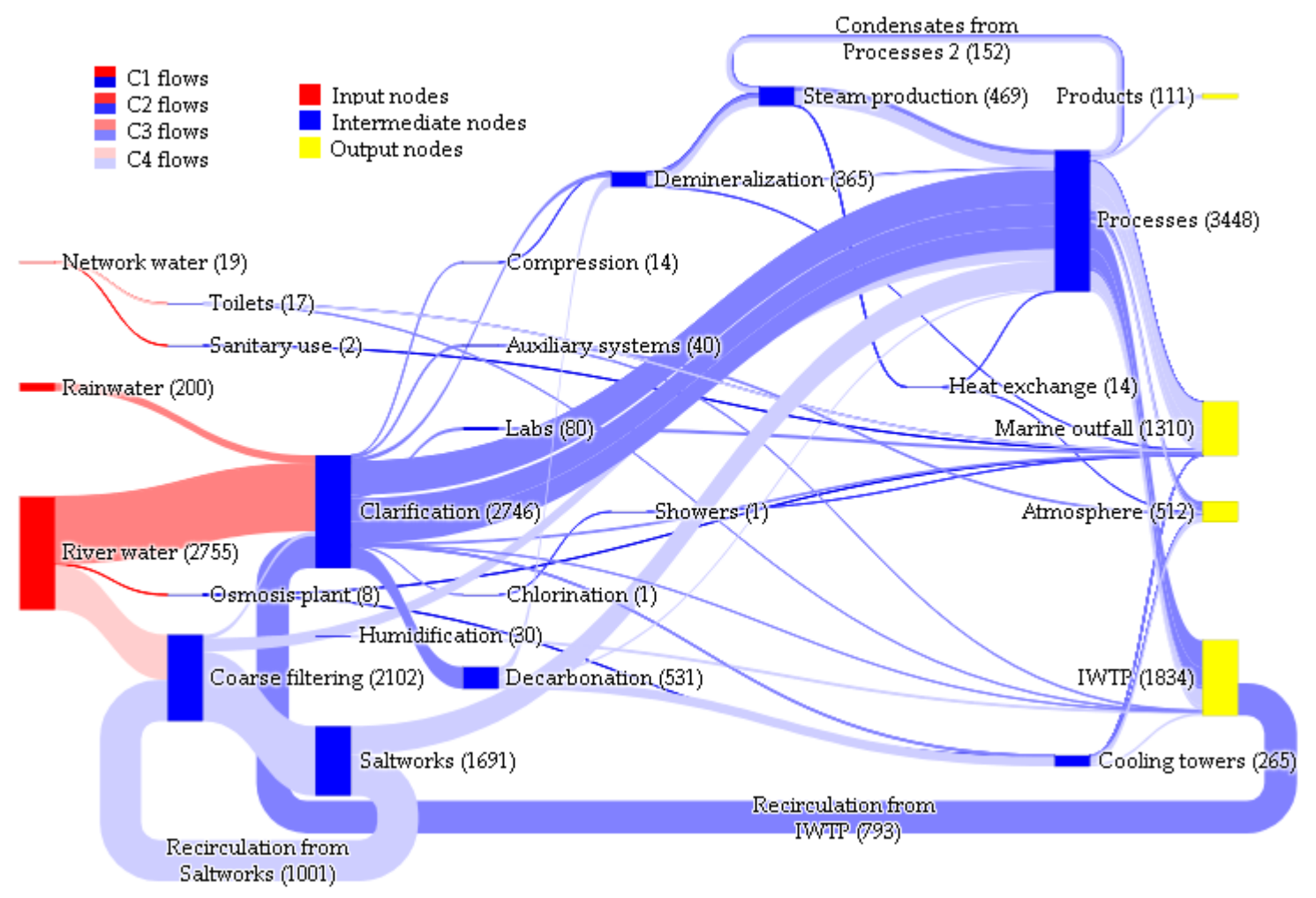

Figure 7. Sankey diagram of water flows in the industrial park after implementing the synergies.

The river water node was also affected by MW3, whereby C1 stopped collecting $8 \mathrm{~m}^{3} / \mathrm{h}$ of well water due to its similarity to the river water collected by the remaining companies in terms of water quality. As a result of these synergies, the river water flow decreased from 3739 to $2755 \mathrm{~m}^{3} / \mathrm{h}$ $(3739-793-200+8)$. In the end, this caused a reduction in the economic costs associated with water catchment fees. These variations also produce alterations in the overall water flows in the industrial park. After the implementation of synergies, the input and output flows continued to be balanced but decreased to $2974 \mathrm{~m}^{3} / \mathrm{h}$. The breakdown of this figure in the case of the inputs was as follows: $2755 \mathrm{~m}^{3} / \mathrm{h}$ from river water, $200 \mathrm{~m}^{3} / \mathrm{h}$ from rainwater and $19 \mathrm{~m}^{3} / \mathrm{h}$ from network water. As for the outputs, the distribution involved $1310 \mathrm{~m}^{3} / \mathrm{h}$ to marine outfall $\left(200 \mathrm{~m}^{3} / \mathrm{h}\right.$ less than before due to the change in rainwater), $512 \mathrm{~m}^{3} / \mathrm{h}$ to the atmosphere and $1041 \mathrm{~m}^{3} / \mathrm{h}$ to IWTP $\left(793 \mathrm{~m}^{3} / \mathrm{h}\right.$ of the total 1834 $\mathrm{m}^{3} / \mathrm{h}$ were recirculated to $\mathrm{C} 4$ coarse filtering).

The remaining indirect synergies related to the supply of either demineralized (MW1) or clarified (MW2) water from one company to others. Although the changes caused by these synergies were not 
noticeable at the scale of the whole system (they would be in the individual diagrams of the companies), they involved 2 demineralizers ( $\mathrm{C} 2$ and $\mathrm{C} 3$ ) and 2 clarifiers (C2 and C4) that were no longer necessary for managing water flows in the industrial park, since other companies had extra capacity to satisfy their needs.

The updated version of the steam Sankey diagram after implementing the synergies identified in Figure 5 resulted in a variety of modifications in relation to Figure 4, whose main impacts were found in the production nodes. On the one hand, MS2 involved C2 that was supplied using steam from the C4 backup gas boiler, once turbined at $13 \mathrm{~kg} / \mathrm{cm}^{2}$. On the other hand, MS4 consisted of C4 supplying C3 needs with steam from backup gas boiling $\left(58 \mathrm{~kg} / \mathrm{cm}^{2}\right)$ and turbined flows $\left(13 \mathrm{~kg} / \mathrm{cm}^{2}\right)$. This caused an increase of $130 \mathrm{t} / \mathrm{h}$ in the gas boiling node, resulting in a final value of $144 \mathrm{t} / \mathrm{h}$ (Figure 8). The gas cogeneration node changed in the same proportion, decreasing to $65 \mathrm{t} / \mathrm{h}$. Hence, the global value of steam produced in the industrial park remained at $469 \mathrm{t} / \mathrm{h}$. The breakdown of this figure into carbon boiling, gas boiling and gas cogeneration evolved from 260,14 and $195 \mathrm{t} / \mathrm{h}$ to 260,144 and $65 \mathrm{t} / \mathrm{h}$, respectively.

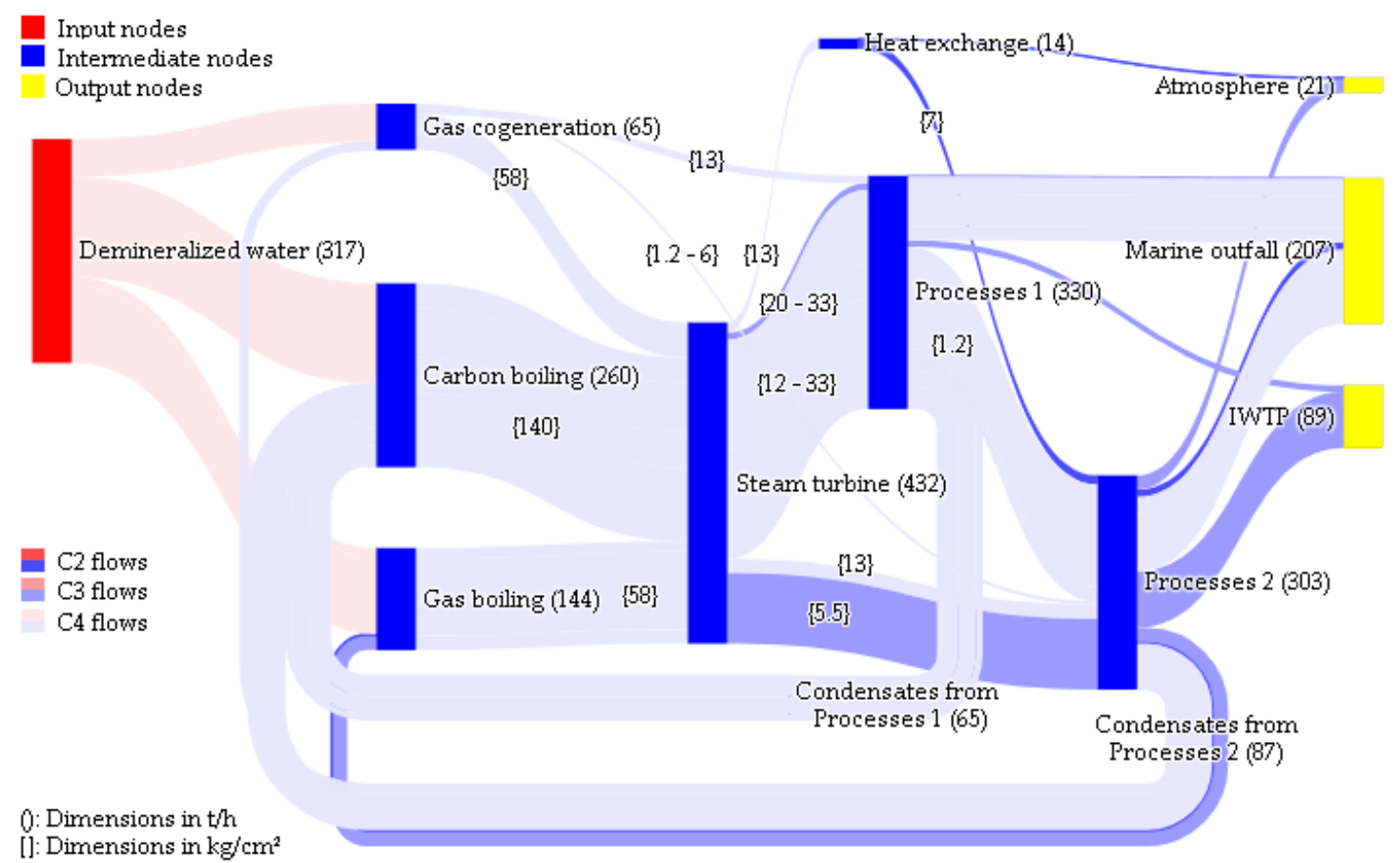

Figure 8. Sankey diagram of steam flows in the industrial park after implementing the synergies.

Apart from their implications in terms of the Sankey diagram, the application of these practices might contribute to optimizing steam consumption in the industrial park. MS2 and MS4 would result in an increase of $144 \mathrm{t} / \mathrm{h}$ in the production of $\mathrm{C} 4$, such that its efficiency would raise up to $88 \%$ ( $27 \%$ more than in the original situation). Since the efficiency of $\mathrm{C} 4$ cogeneration was already high in the starting situation (87\%), both synergies were approached using its backup gas boiler, which would work at $78 \%$ of its nominal capacity ( $144 \mathrm{t} / \mathrm{h}$ out of $185 \mathrm{t} / \mathrm{h}$ ). In terms of equipment, the impacts of these synergies would make the gas boiler used by $\mathrm{C} 2$ and the cogeneration system operated by C3 unnecessary. In turn, this would help to achieve a centralization of steam flows and continuous working regimes, avoiding unnecessary starts and stops that would raise operating costs.

The proposed synergies would also be feasible in what concerns the electric energy strategies taken by $\mathrm{C} 2$ and $\mathrm{C} 3$. As mentioned before, $\mathrm{C} 2$ only focused on the generation of steam, whilst C3 sold its energy to the national electrical grid. The convenience of these synergies would be justified by the dependence of $\mathrm{C} 3$ action plan on the fluctuations in demand and supply, whereby the cost effectiveness of its production would not be stable enough as to dissuade the consideration of alternatives involving global benefits such as these. The energy consumed by $\mathrm{C} 3$ in its own processes would remain constant, 
since the steam turbine from which it stemmed (Table 2) continued to produce electricity after the consideration of synergies.

\subsection{Contribution to Achieving the UN Sustainable Development Goals}

The consideration of the synergies compiled in Figure 5 resulted in a series of modifications in the material, water and steam flows of the industrial park under study. The implications of such changes in terms of sustainability can be addressed using the SDGs as a benchmark. Table 6 provides a summary of the specific targets to which the implementation of IS synergies as those described above might contribute.

Some of these targets were conceptually similar, such as 3.9, 6.3, 11.6 and 12.4, but differed in line with the perspective from which they were considered. Thus, the amount of waste and air and water emissions avoided due to the application of the proposed synergies can contribute to both protecting the welfare of living beings, controlling water quality, reducing environmental impacts on cities and optimizing consumption and production patterns.

Another group of targets associated with generic benefits derived from the synergies identified were $7.3,8.4,9.4,12.2$ and 12.5, since they all concerned resource efficiency, either in terms of energy, raw materials, water or waste management. As a result, the IS opportunities found in the industrial park might strengthen sustainable and modern energy, economic growth, industry and infrastructure innovation and conscientious consumption and production. In the same vein, synergies SW1, SW3, MW1, MW2 and MW3 contributed to achieving water-use efficiency in the form of sustainable withdrawals and the supply of freshwater (target 6.4). The recirculation processes involved in these water-related synergies also helped to mitigate marine pollution, thereby having a positive impact on life below water through target 14.1.

Finally, there is a last group of targets focusing on the main strengths of the approach taken, consisting of the systemic assessment of entire industrial parks. The results collected in this research can inspire other companies to adopt these kinds of strategies (target 12.6), thereby contributing to extending the benefits of IS at local and regional scales. In such cases, the broader implementation of these practices might favour the stability of industry-based economies (target 17.13), serving as an exemplar for other regions in the adoption of policies oriented to promote sustainable development (target 17.14).

The impacts of these links on economic and environmental terms were quantifiable in some cases, depending on data availability regarding costs, emissions and the processes in the industrial park. Table 7 summarises the approximate economic and/or environmental savings associated with these cases, which corresponded to the following synergies: SM4 (brine), SW3 (river water), MS3 (cogeneration system), SM1 (dolomite) and MW2 (clarifiers). These values were combined using 2011 as a baseline, in accordance with the year when data were collected. In the case of economic values, first was their conversion into 2011 figures according to the inflation rates of the corresponding currency. Then, the 2011 values were transformed into EUR and multiplied by the amount of materials, water or steam saved, as indicated in Table 7. Finally, these results were updated again based on inflation rates to obtain 2020 savings.

Table 7. Estimates of the economic and environmental savings associated with computable synergies.

\begin{tabular}{|c|c|c|c|c|}
\hline Concept & Amount (Year) & Savings & 2020 Savings (SI) & References \\
\hline Brine & $8965 t$ & 0.21 (2015) \$/gallon (962 gallons/t) & $195 € / t$ & [38] \\
\hline River water & $8,619,840 \mathrm{~m}^{3}$ & $0.02(2007) € / \mathrm{m}^{3}$ & $0.024 € / \mathrm{m}^{3}$ & [39] \\
\hline Cogeneration & $719,300 \mathrm{MWh}$ & $\begin{array}{c}40(2010) £ / \mathrm{kW} ; 0.26 \mathrm{~kg} \mathrm{CO}_{2} \\
\text { eq./kWh }\end{array}$ & $\begin{array}{c}57.96 € / \mathrm{kW} ; 0.26 \mathrm{t} \\
\mathrm{CO}_{2} \text { eq./MWh }\end{array}$ & {$[40,41]$} \\
\hline Dolomite & $2650 t$ & $0.91+\mathrm{CO}_{2}$ eq. $/ \mathrm{t}$ & $0.91+\mathrm{CO}_{2}$ eq./t & [42] \\
\hline Clarifiers (2) & - & 21,140 t $\mathrm{CO}_{2}$ eq./yr. & 21,140 t $\mathrm{CO}_{2}$ eq./yr. & [43] \\
\hline
\end{tabular}


The production costs associated with brine were estimated at EUR 0.21/gallon (2015), which involves 962 gallons/t [38]. Since the amount of brine saved during a year was $8965 t$, the economic savings associated with this exchange (Figure 6) were EUR 1,755,670/yr. (2020). As for the second flow, the amount of river water required after the implementation of the synergies was reduced to $984 \mathrm{~m}^{3} / \mathrm{h}$ due to the recirculation of wastewater. Considering a collection cost of EUR 0.02/ $\mathrm{m}^{3}$ (2007) [39] and a continuous operating regime throughout the year $(8760 \mathrm{~h}$ ), this would result in EUR 208,332/yr. (2020).

Regarding the steam flow, data in the industrial park were limited in what concerns the gas boiler used by $\mathrm{C} 2$, such that the economic calculations only applied to the gas cogeneration system in $\mathrm{C} 3$, which was no longer necessary after implementing the synergies depicted in Figure 5. The cogeneration system, which produced 719,300 MWh/yr., involved GBP 40/kW (2010) [40] in terms of operation and maintenance. Consequently, this resulted in GBP 4,499,035 (2020) saved per year with a continuous work regime ( $8760 \mathrm{~h} / \mathrm{yr}$.). Overall, the implementation of these synergies would result in an annual economic improvement in the industrial park of EUR 6,463,037/yr. (2020).

Similar calculations were carried out to determine the emissions saved due to the synergies, expressed in $\mathrm{t} \mathrm{CO}_{2}$ eq. Dolomite involved $0.91 \mathrm{tCO}_{2}$ eq. per $\mathrm{t}$ saved [42], which yielded $2411 \mathrm{t} \mathrm{CO}_{2}$ eq./yr. when considering the annual amounts used in the industrial park (Figure 6). Based on the study carried out by Heffernan et al. (2012) [43], the annual emissions associated with the two clarifiers avoided thanks to MW2 could be estimated in 21,140 $\mathrm{t} \mathrm{CO}_{2}$ eq./yr.

Since the cogeneration system in $\mathrm{C} 3$ produced $719,300 \mathrm{MWh} / \mathrm{yr}$. and the emissions associated with this process were $0.26 \mathrm{~kg} \mathrm{CO}_{2} \mathrm{eq} . / \mathrm{kWh}$ [41], the environmental savings in the steam flow were $187,010 \mathrm{t} \mathrm{CO}_{2}$ eq./yr. Again, the effects of the remaining synergies were not taken into account because of the lack of data to determine their corresponding emissions. Hence, the calculable environmental savings in the industrial park amounted to $210,561 \mathrm{t} \mathrm{CO}_{2}$ eq./yr.

The financial balance (incomes-expenses) and consumption expenses (raw materials, supplies and commodities) of the industrial activity in the city where the park was located were EUR 33,292,281 and EUR 868,798,157 in 2011, respectively [44]. Thus, the economic savings derived from the subset of the synergies quantified above (EUR 5,850,672/yr. (2011)) would mean $17.57 \%$ and $0.67 \%$ of these values at that time. Considering the limited number of synergies from which they stem, these rates provide evidence of the capacity of these companies to be the cornerstone for future IS developments in the city. To illustrate how the consideration of plausible IS practices might result in important benefits if applied at larger scales, the savings associated with this subset of synergies, expressed as a percentage, were applied to regional and national scales. Hence, the figures calculated above would reduce to $3.65 \%$ and $0.14 \%$ when referred to the region (autonomous community in Spanish), since $20.77 \%$ of its industrial production corresponded to the city of the industrial park [44]. In turn, the economic savings associated with the proposed synergies would mean $0.05 \%$ of the Gross Domestic Product (GDP) of the region, which was EUR 12,622,706k in 2011 [45]. Finally, taking into account that this region was responsible for 1.1\% of the total GDP of Spain in 2011 (EUR 1,069,323M) [46], if the effects of the subset of quantifiable synergies were applied to the scale of the whole country, the economic savings would amount to approximately EUR 500M.

In the case of emissions, there were no available records of the environmental performance of the companies in the industrial park. Instead, the Spanish Inventory System provided data about the region where the park was located, which released 6,310,000 $\mathrm{t} \mathrm{CO}_{2}$ eq. during 2011 [47]. Hence, the environmental savings calculated for the subset of quantified synergies would amount to $3.34 \%$ of the Greenhouse Gas (GHG) emissions of the region, since they were equivalent to $190,610 \mathrm{t} \mathrm{CO}_{2}$ eq./yr. in 2011. Again, if the subset of actions calculated above as a percentage was proportionally applied to the size of the country, which emitted 358 million $\mathrm{t} \mathrm{CO}_{2}$ eq. in 2011, the emissions avoided in Spain may amount to $11,953,958 \mathrm{t} \mathrm{CO}_{2}$ eq.

The Spanish Government has recently approved its Circular Economy Strategy to reduce the generation of wastes and improve resource efficiency, whereby a series of targets were established to be achieved in 2030, taking the 2010 data as the baseline. These targets included a 30\% reduction in 
the consumption of materials, a $15 \%$ reduction in the generation of waste and a $10 \%$ improvement in water efficiency [48]. At the scale of the industrial park studied, the amount of materials saved and waste diverted from disposal (i.e., including discharged brine) through the proposed synergies was $11,791.4 \mathrm{t}$ (Figure 5). This figure represented $0.39 \%$ of the $3,027,856 \mathrm{t}$ of materials consumed (raw materials, auxiliary materials and auxiliary production services) and $3.33 \%$ of the $353,654 \mathrm{t}$ of wastes generated (hazardous and non-hazardous) (Figure 2). Therefore, more detailed information about potential means of either reducing and reusing wastes as raw materials or extending the lifetime of some products in the park should be collected and analysed to contribute further to meeting the first two objectives. Instead, since the use of water in the park would be reduced by $993 \mathrm{~m}^{3} / \mathrm{h}$ out of the initial $3,739 \mathrm{~m}^{3} / \mathrm{h}(26.55 \%)$ when implementing the synergies related to the replacement of river water (Figure 5), the water-related target would be amply met.

\section{Conclusions}

This research took the activity of an industrial park located in the north of Spain to undertake a systemic analysis of co-located Industrial Symbiosis (IS) opportunities. To this end, information on the three main flows observed in the park (materials, water and steam) was collected from public data of its main companies and guided visits to their facilities. Next was the proposal and analysis of direct (exchange or substitution) and indirect (share or mutuality) synergies to improve the sustainability of the industrial park and explore its potential for future scaling-up.

As a result, 9 direct ( 4 materials, 4 water and 1 steam) and 9 indirect ( 5 materials, 3 water and 1 steam) synergies were identified during the study. Since 6 of them were discarded because of the lack of some data and/or their incompatibility with other cooperation opportunities, the industrial park was subject to a series of synergies that produced several changes in its flows. These changes involved the following savings per year: $2826.4 \mathrm{t}$ of virgin materials replaced by compatible wastes (176.4 $\mathrm{t}$ of calcium carbonate and $2650 \mathrm{t}$ of dolomite), $8965 \mathrm{t}$ of brine replaced by used brine that otherwise would be discharged into water bodies, 8,619,840 $\mathrm{m}^{3}$ of river water, 2 clarifiers, 1 demineralizer, 1 gas boiler and 1 gas cogeneration system.

Overall, these figures would entail a reduction in the production and operation economic costs of the companies, which in turn would crystallize in environmental savings due to the centralization of flows and the increase in resource efficiency. In this vein, most of the water and steam-related synergies would result in one company ( $\mathrm{C} 3$ and $\mathrm{C} 4$, respectively) maximizing its capacity to act as a supply node for the whole industrial park. In turn, this increased efficiency would result in a reduction in the production unitary costs in this company, thereby putting it in a position to achieve competitive selling prices. This would justify the remaining companies in the park putting aside some of their equipment, such that purchasing from those supply nodes might be more profitable for them than generating their own production services. The importance of these synergies would be especially remarkable due to the connection among flows, whereby water performed as an input in steam, which in turn was partially used for electric energy purposes.

Regarding the potential contributions of the selected synergies, only some of them could be turned into preliminary economic and environmental benefits. Still, this limited quantification of synergies would imply saving EUR 6,463,037 and 210,561 $\mathrm{t} \mathrm{CO}_{2}$ eq. per year in the area where the industrial park is located. The proportional application of these actions to the region in which this area is located would result in $0.05 \%$ of its Gross Domestic Product (GDP) and 3.34\% of its annual Greenhouse Gas (GGE) emissions. Furthermore, when valuing their potential benefits at the scale of the whole country, the implementation of these practices may mean about EUR 500M and more than $10 \mathrm{M} \mathrm{t} \mathrm{CO}_{2}$ eq. saved per year.

Although approximate, the figures determined for Spain provide insight into the large annual economic gains that might be obtained by companies involved in IS practices, as well as the associated important benefits for the environment. In this vein, the selected synergies would result in reductions of $0.39 \%, 3.33 \%$ and $26.55 \%$ in the materials consumed, waste generated and water used in the industrial 
park, respectively, thereby contributing to meeting the targets established in the Spanish Circular Economy Strategy for 2030, especially concerning water efficiency. Apart from this quantification, the applied synergies were also analysed in terms of their contributions to achieving the Sustainable Development Goals (SDGs). In total, they proved to be in line with 9 SDGs and 14 of their more specific targets. The cascade effect inherent to these synergies explained the extension of their obvious benefits for the industry to other areas, such as water pollution, clean energy, economic growth, responsible consumption and production, sustainable cities and policy coherence.

The results achieved in this investigation are presented as a proof of the potential benefits of IS at different scales and under the perspective of the three pillars of sustainability: economy, environment and society. In this sense, they also served to prove the main assumption of the study, whereby the city council requesting it expected that the analysis of these large companies may lay the foundations for designing future IS strategies to strengthen the economy, environment and people's welfare in the area. Hence, new schemes of industrial production systems and retrofitting of industrial parks based on the collaboration and partnerships of companies are highly recommended as the keys to future business success. In addition, these approaches can improve both private and public decision-making and support funding allocation, as well as raise awareness and provide reputational benefits and marketing advantages. In the end, these outputs are expected to contribute to shedding light on the multiple positive impacts associated with the promotion of IS policies by governments and public entities. Despite its contributions with respect to recent related literature, this research still needs further development in what concerns the automation of the systemic identification and analysis of IS opportunities, in order to facilitate their future implementation.

Supplementary Materials: The following are available online at http://www.mdpi.com/2071-1050/12/14/5802/s1, Table S1: Summary of the questionnaire distributed in the industrial park to collect materials data. Table S2: Summary of the questionnaire distributed in the industrial park to collect water data. Table S3: Summary of the questionnaire distributed in the industrial park to collect steam data.

Author Contributions: Conceptualization, C.R.-P.; data curation, D.J.-E.; formal analysis, D.J.-E. and C.R.-P.; funding acquisition, C.R.-P.; methodology, C.R.-P.; project administration, C.R.-P.; software, D.J.-E.; supervision, C.R.-P.; visualization, D.J.-E.; writing—original draft preparation, D.J.-E.; writing—review and editing, D.J.-E. and C.R.-P. All authors have read and agreed to the published version of the manuscript.

Funding: This research was funded by the Spanish Ministry of Science, Innovation and Universities, grant number DPI2017-88127-R (AEI/FEDER, UE).

Conflicts of Interest: The authors declare no conflict of interest.

\section{References}

1. Potocnik, J.; Teixeira, I. Resource Efficiency for Sustainable Development: Key Messages for the Group of 20; UN Environment, International Resource Panel: Paris, France, 2018.

2. Hatfield-Dodds, S.; Schandl, H.; Newth, D.; Obersteiner, M.; Cai, Y.; Baynes, T.; West, J.; Havlik, P. Assessing global resource use and greenhouse emissions to 2050, with ambitious resource efficiency and climate mitigation policies. J. Clean. Prod. 2017, 144, 403-414. [CrossRef]

3. Kusch, S. Industrial Symbiosis: Powerful Mechanisms for Sustainable Use of Environmental Resources; The Global Sustainable Development Report (GSDR): Ulm, Germany, 2015.

4. El-Haggar, S.M. Chapter 10-Sustainability of industrial waste management. In Sustainable Industrial Design and Waste Management, 1st ed.; Academic Press: Oxford, UK, 2007; pp. 307-369, ISBN 978-0-12-373623-9.

5. Kapur, A.; Graedel, T.E. Industrial ecology. In Encyclopedia of Energy; Elsevier: New York, NY, USA, 2004; pp. 373-382, ISBN 978-0-12-176480-7.

6. Cervantes, G. A methodology for teaching industrial ecology. Int. J. Sustain. High. Educ. 2007, 8, $131-141$. [CrossRef]

7. Schroeder, P.; Anggraeni, K.; Weber, U. The relevance of circular economy practices to the sustainable development goals. J. Ind. Ecol. 2019, 23, 77-95. [CrossRef]

8. Betts, K.S. Environmental news: Quantifying industrial symbiosis. Environ. Sci. Technol. 2005, 39, 354-360. [CrossRef] [PubMed] 
9. Taddeo, R.; Simboli, A.; Ioppolo, G.; Morgante, A. Industrial symbiosis, networking and innovation: The potential role of innovation poles. Sustainablity 2017, 9, 169. [CrossRef]

10. Neves, A.; Godina, R.G.; Azevedo, S.; Pimentel, C.C.O.; Matias, J. The potential of industrial symbiosis: Case analysis and main drivers and barriers to its implementation. Sustainability 2019, 11, 7095. [CrossRef]

11. Velenturf, A.P.M.; Jensen, P.D. Promoting industrial symbiosis: Using the concept of proximity to explore social network development. J. Ind. Ecol. 2016, 20, 700-709. [CrossRef]

12. Chertow, M.R. Industrial symbiosis: Literature and taxonomy. Annu. Rev. Energy Environ. 2000, 25, 313-337. [CrossRef]

13. Deutz, P.; Lyons, D.I. Editorial: Industrial symbiosis-an environmental perspective on regional development. Reg. Stud. 2008, 42, 1295-1298. [CrossRef]

14. Lowe, E.A. Creating by-product resource exchanges: Strategies for eco-industrial parks. J. Clean. Prod. 1997, 5, 57-65. [CrossRef]

15. Le Tellier, M.; Berrah, L.; Stutz, B.; Audy, J.-F.; Barnabé, S. Towards sustainable business parks: A literature review and a systemic model. J. Clean. Prod. 2019, 216, 129-138. [CrossRef]

16. Porter, M.; Ketels, C. Clusters and industrial districts: Common roots, different perspectives. In A Handbook of Industrial Districts; Edward Elgar Publishing: Cheltenham, UK, 2009.

17. Asheim, B.T.; Isaksen, A. Location, agglomeration and innovation: Towards regional innovation systems in Norway? Eur. Plan. Stud. 1997, 5, 299-330. [CrossRef]

18. Côté, R.P.; Cohen-Rosenthal, E. Designing eco-industrial parks: A synthesis of some experiences. J. Clean. Prod. 1998, 6, 181-188. [CrossRef]

19. Haskins, C. Multidisciplinary investigation of eco-industrial parks. Syst. Eng. 2006, 9, 313-330. [CrossRef]

20. Haskins, C. A systems engineering framework for eco-industrial park formation. Syst. Eng. 2007, 10, 83-97. [CrossRef]

21. Haskins, C. The story of verdal-how one intelligent community uses systems engineering to enable sustainable development. In Proceedings of the 17th Annual International Symposium of the International Council on Systems Engineering, INCOSE 2007-Systems Engineering: Key to Intelligent Enterprises, San Diego, CA, USA, 24-28 June 2007; Volume 3, pp. 1465-1475.

22. Sopha, B.M.; Fet, A.M.; Keitsch, M.M.; Haskins, C. Using systems engineering to create a framework for evaluating industrial symbiosis options. Syst. Eng. 2010, 13, 149-160.

23. Romero, E.; Ruiz, M.C. Framework for applying a complex adaptive system approach to model the operation of eco-industrial parks. J. Ind. Ecol. 2013, 17, 731-741. [CrossRef]

24. Deshpande, P.C.; Aspen, D.M. A framework to conceptualize sustainable development goals for fishing gear resource management. In World Sustainability Series; Springer: Berlin, Germany, 2018; pp. 727-744.

25. Ginige, A. Systems Engineering approach to smart computing: From farmer empowerment to achieving sustainable development goals. In Proceedings of the International Research Conference on Smart Computing and Systems Engineering-SCSE 2018, Kiribathgoda, Sri Lanka, 29 March 2018; pp. 1-4.

26. Moldavska, A.; Welo, T. A Holistic approach to corporate sustainability assessment: Incorporating sustainable development goals into sustainable manufacturing performance evaluation. J. Manuf. Syst. 2019, 50, 53-68. [CrossRef]

27. Brooks, I. The United Nations Sustainable Development goals in systems engineering: Eliciting sustainability requirements. In Proceedings of the International Conference on ICT for Sustainability (ICT4S), Bristol, UK, 21-27 June 2020; Association for Computing Machinery (ACM): New York, NY, USA, 2020; Volume 7, pp. 1-8.

28. Casals, M.; Roca, X.; Forcada, N. Diseño de complejos industriales, 1st ed.; Iniciativa Digital Politecnica, Ed.; Universitat Politecnica de Catalunya (UPC): Barcelona, Spain, 2008; ISBN 9788476537428.

29. Stéphane, O.; Jean-Baptiste, Q.; Charles-Xavier, S.; Gwenaël, L.M.; Mouad, M.; Alexandre, B. A cross-sectorial synergies identification methodology for industrial symbiosis. In Proceedings of the Smart Innovation, Systems and Technologies; Springer Science and Business Media Deutschland GmbH: Berlin, Germany, 2019; Volume 155, pp. 229-240.

30. Soundararajan, K.; Ho, H.K.; Su, B. Sankey diagram framework for energy and exergy flows. Appl. Energy 2014, 136, 1035-1042. [CrossRef] 
31. Sankey, H.R. The thermal efficiency of steam engines. Report of the committee appointed to the council upon the subject of the definition of a standard of standars of thermal efficiency for steam engines. Minutes Proc. Inst. Civ. Eng. 1898, 134, 278-312.

32. Schmidt, M. The Sankey diagram in energy and material flow management: Part I: History. J. Ind. Ecol. 2008, 12, 82-94. [CrossRef]

33. Schmidt, M. The Sankey diagram in energy and material flow management-Part II: Methodology and current applications. J. Ind. Ecol. 2008, 12, 173-185. [CrossRef]

34. Griggs, D.; Stafford-Smith, M.; Gaffney, O.; Rockström, J.; Öhman, M.C.; Shyamsundar, P.; Steffen, W.; Glaser, G.; Kanie, N.; Noble, I. Policy: Sustainable development goals for people and planet. Nature 2013, 495, 305-307. [CrossRef] [PubMed]

35. European Commission. Industrial Emissions (Integrated Pollution Prevention and Control); European Parliament and Council of the European Union: Brussels, Belgium, 2010; pp. 17-119.

36. Official State Gazette. Legal Regime for the Reuse of Purified Water; Ministry of the Presidency: Madrid, Spain, 2007; pp. 50639-50661.

37. Official State Gazette. Criteria for Monitoring and Evaluating the State of Surface Sater and Environmental Quality Standards; Ministry of Agriculture, Food and Environment: Madrid, Spain, 2015; pp. 80582-80677.

38. SIMA Calculating True Costs of Salt Brine. Available online: https://www.sima.org/news2/2015/08/01/ calculating-true-costs-of-salt-brine (accessed on 24 March 2020).

39. Hispagua ¿Cuánto Cuesta Al Agua? Available online: http://hispagua.cedex.es/sites/default/files/especiales/ Tarifas_agua/introduccion.html (accessed on 24 March 2020).

40. Electricity Generation Costs Update; Mott MacDonald UK: Brighton, UK, 2010.

41. POSTnote Carbon Footprint of Heat Generation; POSTnote: London, UK, 2016.

42. IPCC. Industrial processes. In Revised 1996 IPCC Guidelines for National Greenhouse Gas Inventories; Houghton, J., Filho, L.M., Lim, B., Treanton, K., Mamaty, I., Bonduki, Y., Griggs, D., Callender, B., Eds.; Intergovernmental Panel on Climate Change: Ginebra, Switzerland, 2003; p. 2.5.

43. Heffernan, B.; Blanc, J.; Spanjers, H. Evaluation of greenhouse gas emissions from municipal UASB sewage treatment plants. J. Integr. Environ. Sci. 2012, 9, 127-137. [CrossRef]

44. Encuesta Industrial de Empresas-Cantabria 2012; ICANE: Santander, Spain, 2013.

45. Informe del Mercado de Trabajo de Cantabria-Datos 2012; Observatorio de las Ocupaciones: Santander, Spain, 2013.

46. INE Contabilidad Regional de España. Available online: https://www.ine.es/dyngs/INEbase/es/operacion. htm?c=Estadistica_C\&cid=1254736167628\&menu=resultados\&idp=1254735576581\#!tabs-1254736158133 (accessed on 4 June 2020).

47. Emisiones de GEI por Comunidades Autónomas a Partir del Inventario Español-Serie 1990-2018; MITECO: Madrid, Spain, 2020.

48. España Circular 2030-Estrategia Española de Economía Circular; MITECO: Madrid, Spain, 2020. 